\title{
CERÁMICA TARDORROMANA MODELADA A MANO DE CARÁCTER LOCAL, REGIONAL Y DE IMPORTACIÓN EN LA PROVINCIA DE ALICANTE*
}

\author{
PAUL REYNOLDS \\ Institute of Archeology, London
}

\begin{abstract}
En este artículo presentamos una tipología y cronología de la cerámica tardo-romana modelada a mano de carácter local, regional y de importación en los yacimientos del valle del Río Vinalopó (Alicante). Se trata de la producción y distribución de la cerámica de los distintos centros, con referencia particular a los paralelos etnográficos modernos. Proponemos la continuidad de ciertas forma tardo-romanas durante época islámica, y examinaremos brevemente la cronología de los yacimientos y la cerámica islámica en esta región hasta el siglo XY.
\end{abstract}

\begin{abstract}
In this paper we present a typology and chronology of local, regional and imported late roman handmade pottery from sites in the valley of the River Vinalopó (Alicante). The production and distribution of the wares are discussed, with particular reference to modern ethnographic parallels. The continuity of certain late roman handmade forms into the islamic period is proposed, together with a brief examination of the chronology of local islamic sites and pottery from the 8 th to XIth centuries.
\end{abstract}

Como avance de la publicación de nuestra tesis doctoral sobre la arqueología tardorromana en el valle del río Vinalopó, nos ha parecido conveniente proporcionar algunos datos sobre un tipo de cerámica que en algunos casos se ha reconocido como tardorromano (LLOBREGAT, 1970, 190; RAMOS FERNÁNDEZ, 1975, 257-260; 1983, 147-154), pero que hasta ahora no ha sido el objeto de un estudio detallado.

El estudio de la cerámica común romana en la zona ha sido difícil, en parte por la ausencia casi total de trabajos sobre la cerámica romana común y fina que encontramos al comenzar nuestra investigación (LLOBREGAT, 1967; POVEDA NAVARRO, inédito; SÁNCHEZ FERNÁNDEZ, 1983), y más aún por el poco interés en la arqueología romana en general, de que se lamentaba recientemente ABAD CASAL (1983, 1984), aunque al menos se ha definido una línea en esta dirección con la publicación de trabajos recientes (GONZÁLEZ PRATS, 1985; POVEDA NAVARRO y RIBERA LACOMBA, 1985; SÁNCHEZ DE PRADO, 1985;
SÁNCHEZ FERNÁNDEZ y LOBREGAD COLLADO, 1985) y con el anuncio de otros varios: la Fonteta de Guardamar por Azuar Ruiz; la necró-

* Quiero aquí recordar y dar las gracias a todos aquellos que me ayudaron durante mi estancia en Alicante, entre 1983 y 1985, mientras recogía datos para mi tesis doctoral, de que la que ahora publico este pequeño avance y especialmente mostrar mi agradecimiento a los que me permitieron estudiar material inédito de sus propias excavaciones: E. Llobregat Conesa, $\mathbf{R}$. Azuar Ruiz, V. Bernabeu, N. Roselló y M. Benito del Museo Arqueológico Provincial de Alicante, M. J. Sánchez Fernández, A. Guardiola Martínez, E. Blasco Martínez del Museo de Santa Pola; L. Abad Casal, J. Uroz Sáez, M. F. Galiana, M. D. Sánchez de Prado y S. Gutiérrez Lloret de la Universidad de Alicante; R. Ramos Fernández, La Alcudia, Elche; A. Sáez del Grupo Ilicitano de Estudios Arqueológicos, Elche; E. Alberola de Novelda; A. Poveda Navarro del Museo Municipal de Elda; Sección de Arqueología del Centro Excursionista Eldense de Elda; J. M. Soler García del Museo de Villena; J. M. Segura, J. Torro y Abad, J. M. Vicens Petit del Museo Arqueológico de Alcoy; Centre d'Estudis Contestans del Museo Municipal de Cocentaina; P. Lillo Carpio, S. Ramallo Asensio, M. Amante de la Universidad de Murcia. 
polis de Vistalegre (Aspe) por Roselló Cremades; materiales ibéricos y romanos del Museo de Novelda por Galiana Botella y Roselló Cremades; las cerámicas finas de Santa Pola por Guardiola Martínez y Blasco Martínez; y el mío propio sobre los materiales de Benalúa. Además, la Universidad de Alicante tiene previsto un programa extenso de prospecciones en los yacimientos de la zona.

A esto se añade un problema aún mayor, la falta de excavaciones que nos hayan proporcionado una estratigrafía útil. Como veremos, casi la totalidad de la cerámica que manejamos proviene de excavaciones antiguas - que no se han publicado-, o de prospecciones en superficie, y por tanto no podemos referirnos a grupos cerámicos de contextos cerrados.

De todos modos, hemos podido averiguar algo utilizando los datos que se han publicado, más a través de la comparación con los conjuntos cerámicos procedentes de prospecciones o de excavaciones que con el estudio de la distribución de las formas de cerámica fina, que nos ofrecen una cronología más corta o en todo caso diferente (1). Así, hemos podido distinguir, más o menos, la cerámica común de épocas alto imperial, bajorromana, y tardorromana. Como la tesis doctoral era principalmente un estudio de la arqueología tardorromana de la zona, nos hemos centrado en la investigación casi exclusiva de los yacimientos tardorromanos y en la elaboración de una tipología exhaustiva de la cerámica común de esas fechas. En el caso del estudio de las épocas anteriores, solamente hemos intentado proponer una síntesis de los yacimientos y de la cerámica común principal, para mostrar brevemente el desarrollo de la zona antes del siglo V.

Aunque el estudio detallado de los yacimientos formará parte de la tesis doctoral, antes de presentar la tipología de la cerámica modelada a mano, creemos que es necesario hablar algo de los yacimientos «claves» que nos han servido como base para elaborar la tipologia de la cerámica común en general. (Fig. 1)

Para la época alto-imperial nos ha sido muy útil la cerámica de las excavaciones del Tosal de Manises, en donde la falta de t.s. clara $C$ nos indica una fecha final a principios del siglo III; de las antiguas excavaciones de El Monastil (Elda), cuya cerámica

(1) A partir del siglo II la cerámica fina de mayor interés para este estudio ha sido la cerámica t. s. clara / African Red Slip Ware, que aquí abreviamos ARS (HAYES, 1972; 1980. LAMBOGLIA 1958; 1963. fina se agrupa principalmente en dos épocas, los siglos I y V d. C. (Ver REYNOLDS, inédito; POVEDA NAVARRO y RIBERA Y LACOMBA, 1985; Sección de Arqueología-C. E. E., 1972); la Isleta de Campello; la villa romana de La Ermita de Fontcalent; los materiales de prospecciones de varias villas romanas en el Campo de Elche, Villena, Sax y Elda; las excavaciones de dos balsas romanas en Santa Pola (SÁNCHEZ FERNÁNDEZ, 1983 y GONZÁLEZ PRATS, 1985) con un relleno correspondiente quizá a principios del siglo VI, época de la que hay una pequeña cantidad de cerámica, pero que presenta también materiales anteriores al siglo VI; y finalmente la cerámica de las excavaciones de Illici (La Alcudia).

Ha sido difícil definir la cerámica perteneciente a los siglos III y IV, teniendo como referencia solamente los materiales de prospección de las villas y la cerámica de las excavaciones de La Alcudia y de las balsas de Santa Pola. Nuestro criterio para la identificación de cerámica de esta época ha sido su ausencia en los yacimientos que se desarrollan solamente durante la época alto imperial (Tosal de Manises, la Isleta de Campello, El Monastil, y algunas villas) o aquellos otros que tienen una cronología a partir del siglo $\mathrm{V}$.

En época tardorromana, nuestras prospecciones nos indican la existencia en el siglo $\mathrm{V}$ de un fuerte asentamiento, o reocupación en algunos casos, de yacimientos de altura como el Castillo de Santa Bárbara (Alicante), La Moleta (Elche), Castillo del Río (Aspe), El Sambo (Elda), Cámara (Elda), El Monastil (Elda), Els Castellarets (Petrel) aunque la mayoría de estos yacimientos se desarrollan también durante el siglo VI (Castillo de Santa Bárbara, La Moleta, Castillo del Río, El Sambo, Els Castellarets). El yacimiento de El Castellar (Elche) está incluido en este grupo, pero hasta ahora no hay indicaciones de un asentamiento en el siglo $\mathrm{V}$, aunque hemos recogido cerámica alto-imperial. Debemos señalar también que en contra de lo que se ha propuesto siempre (LLOBREGAT, 1976; 1977; 1980; 1983 a; 1983 b. AZUAR RUIZ, 1983, 367) en el Monastil, el ARS no sobrepasa fechas del siglo V (REYNOLDS, inédito) y no puede tener relación con la sede episcopal de Ello, aunque, no obstante, estamos de acuerdo con estos autores en la identificacion de este yacimiento con el obispado, por otras razones (vid infra).

El asentamiento en yacimientos de altura durante la época tardorromana en la zona no es un caso ais- 
lado, sino que se encuentra también en los yacimientos tardíos de El Castellar (Alcoy) (ver TORRO Y ABAD, 1984), Castell de Castalla (CERDÁ BORDERA, 1983, 87) y El Cabezo de Roenas / Begastrum (Cehegín, Murcia) (GONZÁLEZ BLANCO y otros, 1983. ABELLÁN SORIANO y otros, 1984). Es un fenómeno también reconocido en Italia (POTTER, 1979, capítulo 6) y Sicilia (conversación con J. Johns, Universidad de Newcastle).

Los yacimientos de El Monastil y La Moleta, donde hay abundancia de ARS del siglo $\mathrm{V}$ han proporcionado cerámica común que nos ha servido como base para la tipología de la cerámica común del siglo V; la cerámica común de las balsas de Santa Pola ha sido otro interesante punto de referencia.

Para la tipología de la cerámica común de los finales del siglo $\mathrm{V}$ y la primera mitad del siglo VI, la fuente principal y punto de partida de todo nuestro trabajo ha sido la cerámica fina y común de un vertedero tardorromano excavado en el barrio de Benalúa (Alicante) en 1971 (REYNOLDS, en prensa). Otro vertedero, probablemente contemporáneo, con escombros de una fábrica de vidrio, fue excavado por el autor a unos $100 \mathrm{~m}$. del primero (REYNOLDS, en prensa). El yacimiento de La Alcudia/Illici nos ha permitido ampliar el repertorio de formas de los siglos $\mathrm{V}$ y VI, pero partiendo de los modelos ya proporcionados por la cerámica de otros yacimientos como Benalúa, El Monastil y La MOleta, porque casi todo el material de dicho yacimiento carece de una referencia estratigráfica segura.

\section{CERÁMICA MODELAdO A MANO Y A TORNO LENTO}

Es frecuente, junto a la cerámica hecha a torno, la aparición de cerámica modelada a mano y a torno lento, de producción local o regional, en los conjuntos cerámicos de los yacimientos tardorromanos de toda la región. Como veremos, hay casos en los que se produce una importación de esta clase de cerámica pero, como es lógico, se limita a una distribución costera en general.

Como FULFORD y PEACOCK (1984), incluimos la cerámica hecha a torno lento en el grupo de cerámica modelada sin torno porque, según los paralelos etnográficos y los estudios de cerámica romana en otras regiones, la cerámica hecha a torno lento puede compartir el mismo nivel de producción y distribución y la misma importancia en la econo- mía de la sociedad que la fabrica, que la cerámica hecha a mano. En contraste, la cerámica hecha a torno es un claro indicador de un nivel bastante más desarrollado, que busca otra clase de mercado y que tiene mayor entidad en la economía de los productores.

En el estudio de la cerámica común no nos hemos detenido simplemente en el estudio de las distintas formas de la cerámica. Por el contrario, hemos prestado especial atención a las varias pastas y técnicas de modelado, con la intención de aislar lo que es, en efecto, la «línea» de formas hechas con una misma técnica característica de uno u otro centro de producción (No puedo encontrar un paralelo español para la palabra inglesa «ware», que denomina una clase de cerámica con características personales). En el caso de la cerámica local o regional hemos podido distinguir la cerámica de por lo menos cinco grupos distintos, para lo que se ha empleado una lupa de potencia $\times 20$.

A continuación, pasaremos a describir los varios tipos de cerámica hecha a torneta o a mano que encontramos en la zona, con un resumen de su distribución y fechas posibles, y posteriormente hablaremos de los numerosos aspectos y problemas que han surgido como resultado de este estudio.

\section{CERÁMICA DE IMPORTACIÓN}

\section{Grupo 1}

Fulford Handmade Fabric I.I (FULFORD y PEACOCK, 1984, 8-10, 157, 159, figs. 55 y 56, Forms 1-7. PEACOCK, 1982, 79-80). Cerámica hecha a torno lento. Bruñida al exterior. Superficies marrón-rojizas o negras en las que se aprecian pequeñas fracturas debidas a los desengrasantes. La pasta es marrón-rojiza oscura, granulosa, con fractura accidentada. Abundante desengrasante, el más característico de los cuales es de un mineral semiopaco, regular, con fractura laminosa (hasta $2 \mathrm{~mm}$., de frecuencia moderada, que según FULFORD y PEACOCK (1984, 9-10) es un tipo de feldespato, aunque también hay cuarzo semi-redondeado y opaco (frecuencia moderada) y cal (I-2mm., poco frecuente).

De las siete formas de esta pasta en la tipología de Fulford, sólo tenemos ejemplares de dos.

Forma 1.1 (fig. 2, 1-3. FULFORD y PEACOCK, 1984, 157, fig. 55, Form 1): Fuente con borde engrosado al exterior, pared recta y fondo 


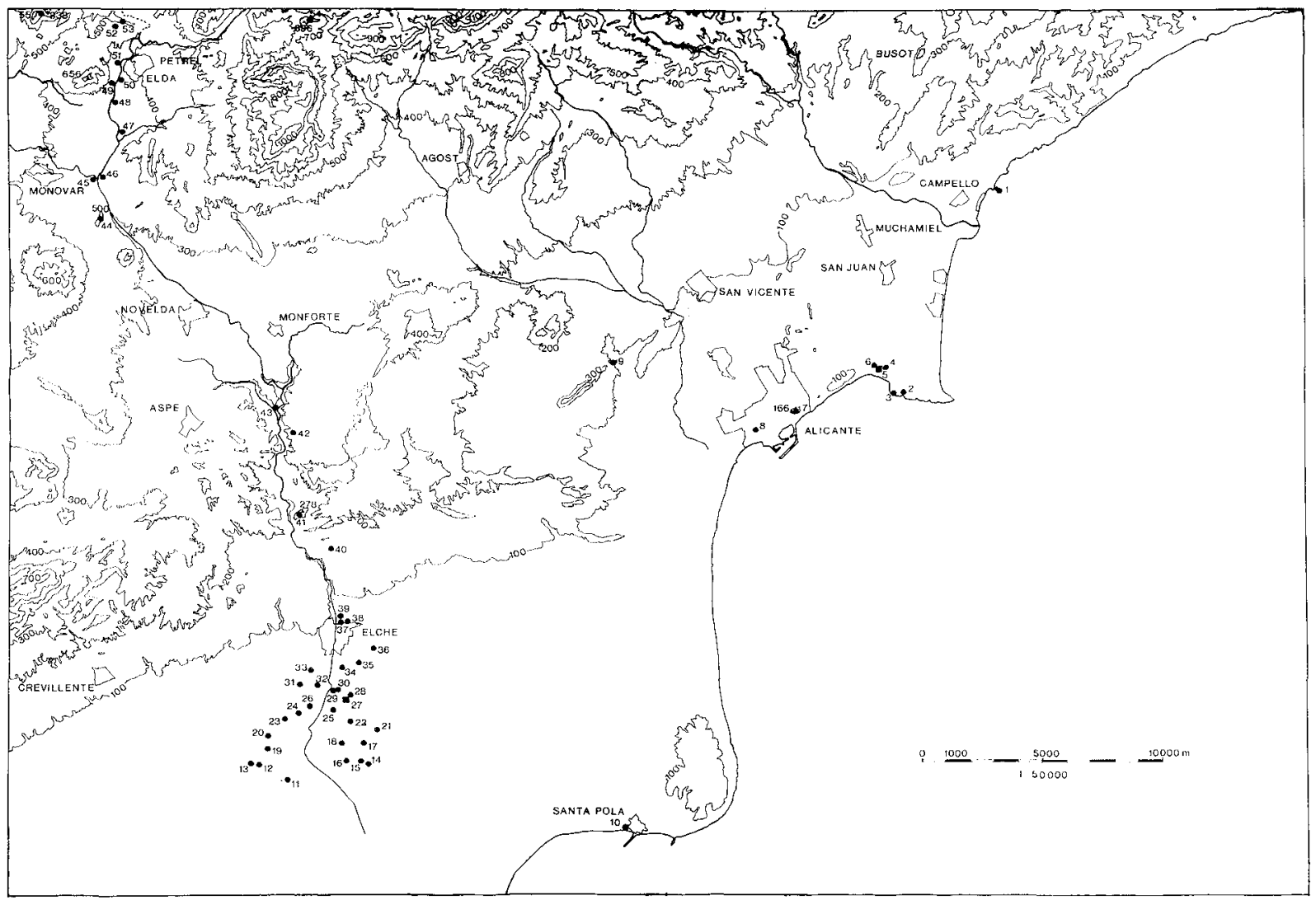

Fig. 1: Los yacimientos romanos del Medio y Bajo Vinalopó. En la lista siguiente se señala con una asterisco los yacimientos de los que hemos estudiado cerámicas de prospección o excavación.

1. La Isleta de Campello. Villa, factoría de salazones.

* 2. Edificio alto imperial.

3. Almadraba romana (?)

* 4. Villa romana cerca del Tosal de Manises.

* 5. Tosal de Manises. Ciudad. Municipios.

6. Cerro de Las Balsas. Yacimiento romano (?) Lugar donde se hallaron reutilizadas dos losas labradas de época visigoda.

* 7. Castillo de Santa Bárbara.

* 8. Vertederos tardorromanos (Benalúa, 1972 y 1983). Escorias de una fábrica de vidrio tardorromana. Para una descripción de los otros hallazgos en la zona ver ABAD CASAL (1984, 108 en adelante). ¿Mansio? o ¿municipium?

* 9. Villa romana de La Ermita de Fontcalent.

* 10. Puerto de Santa Pola: balsas y almacenes romanos.

* 11. Casa del León. Villa probable. (No pudimos localizar este yacimiento) (RAMOS FERNÁNDEZ, 1976, n. $\left.{ }^{\circ} 24\right)$.

12. Orts. (RAMOS FERNÁNDEZ, 1976, n. ${ }^{\circ} 23$.

13. Sempere. (RAMOS FERNÁNDEZ, 1976, n. ${ }^{\circ} 22$.

14. Yacimiento (RAMOS FERNÁNDEZ, 1975, LAM. IV, p. 60).

15. Farsiure. Villa (RAMOS FERNÁNDEZ, 1976, n. ${ }^{\circ}$ 14).
* 16. Hacienda de Agulló. Villa (RAMOS FERNÁNDEZ, n. $\left.{ }^{\circ} 15\right)$. Encontramos cerámica en superficie.

17. Botella. Villa (RAMOS FERNÁNDEZ, 1976, n. ${ }^{\circ} 13$ ).

18. Ventorillo de Carabases / Doña Nieves. Cerámica solamente donde RAMOS FERNÁNEZ localiza su n. ${ }^{\circ} 11(1976$, nos. 11 y 12). Una villa y cementerio.

19. Selva (RAMOS FERNÁNDEZ, 1976, n. ${ }^{\circ} 21$ ).

20. La Loseta (?) Inscripción (romana?). In situ.

21. Asprillas. (RAMOS FERNÁNDEZ, 1976, n. ${ }^{\circ} 10$ ).

* 22. Hacienda de Irlés. Villa. Localizamos el yacimiento un poco más al norte de la zona señalada por RAMOS FERNÁNDEZ $\left(1976, n^{\circ}{ }^{\circ}\right.$ 9) e incluimos como parte del mismo yacimiento la sepultura de Carmohadat (RAMOS FERNÁNDEZ, 1976, n. ${ }^{\circ} 8$ ).

23. Hondo de Alcavó. (RAMOS FERNÁNDEZ, 1976, n. $\left.{ }^{\circ} 20\right)$

24. Hacienda de Canales. (RAMOS FERNÁNDEZ, 1976, n. $\left.{ }^{\circ} 19\right)$.

25. El Alcaldet. Villa. (RAMOS FERNÁNDEZ, 1976, n. ${ }^{\circ}$ ). No pudimos localizar este yacimiento.

* 26. Casa de Mariano Serrano al lado de la carretera. Cerámica alto imperial.

* 27. La Alcudia. Colonia Ilici. Sede episcopal.

28. Pere. Villa (?) (RAMOS FERNÁNDEZ, 1976, n. ${ }^{\circ} 6$ ).

* 29 Huerto de Vizcarra 2. Construcciones y cerámica abundante (alto imperial-siglo V). Localizamos el yacimiento en el punto señalado por RAMOS FERNÁNDEZ $\left(1976, \mathrm{n} .^{\circ}\right.$ 5).

30. Vizcarra 1. Desaparecido debajo de la zona industrial. (RAMOS FERNÁNDEZ, 1976, n. ${ }^{\circ} 4$ ). 
plano. Diámetro: $27-33 \mathrm{~cm}$. Sólo conocemos tres ejemplares de las balsas de Santa Pola y dos de la villa de La Ermita de Fontcalent. Según Fulford puede tener una cronología amplia, desde el siglo I hasta los principios del siglo V. Distribución: Pantelleria, Italia, Sardinia, Túnez.

Forma 1.2 (fig. 2,4. FULFORD y PEACOCK, 1984, 159, fig. 55, Form 3): Cuenco, de cuerpo hemisférico. Dos asas horizontales semilunares. Fulford sugiere unas fechas desde el siglo IV hasta $\mathrm{c}$. 450/475. Distribución: Pantelleria, Túnez. Aquí sólo conocemos un ejemplar del vertedero de Benalúa (1971).

Según Fulford y Peacock estas formas y otras de esta pasta son productos de la Isla de Pantelleria (entre Sicilia y Túnez) (ver p. 27).

\section{Grupo 2.}

Carthage Late Roman Cooking Ware II (HAYES, 1976, 96) / Fulford Handmade Fabric 1.2 (FULFORD y PEACOCK, 1984, 10-11, 159, 161, fig. 56, Forms 8-12): Cerámica modelada a mano. Bruñido más o menos horizontal, pero irregular, sobre las superficies. El ejemplar de Santa Pola (fig. $2,5)$, quizá más antiguo que los demás, está bruñido

31. Hacienda de Verdú. ¿Sepulturas? (RAMOS FERNÁNDEZ, 1976, n. ${ }^{\circ} 17$ ).

32. Hacienda de Torregrosa. Sepultura. (RAMOS FERNÁNDEZ, 1976, n. $\left.^{\circ} 18\right)$.

33. Algorós. Villa. (RAMOS FERNÁNDEZ, 1976, n. ${ }^{\circ}$ 16).

34. Campo de Experimentación Agrícola. Sepulturas. (RAMOS FERNÁNDEZ, 1976, n. ${ }^{\circ} 3$ ).

35. El Pilar. ¿Villa? (RAMOS FERNÁNDEZ, 1976, n. ${ }^{\circ}$ 2).

36. La Coronela. Sepultura. Restos constructivos. (RAMOS FERNÁNDEZ, 1976, n. ${ }^{\circ}$ 1).

37. Parque Infantil. Villa.

38. ¿Villa? (Comunicación personal con R. Ramos Fernández).

39. ¿Villa? (Comunicación personal con R. Ramos Fernández).

* 40. La Moleta.

* 41. El Castellar de la Morera (Elda).

* 42. Castillo del Río (Aspe). ¿En el llano, lugar de la mansio Aspis, de la Via Augusta? Muy poca cerámica alto imperial en el cerro.

* 43. Necrópolis visigoda de Vistalegre (Aspe). Poco material de ajuar: una vasija y broche de cinturón visigodos (siglo VII, según N. Roselló). La cerámica (hecha a mano, del grupo 7, y cerámica pintada) se halló fuera de los enterramientos, y no es necesariamente contemporánea. Si lo fuera, daría una fecha bastante antigua para la cerámica «islámica» pintada (presente en El Sambo). con bandas irregulares, y es único en este respecto. El color de las superficies varía entre marrón claro-anaranjado, marrón-rojizo, marrón oscuro, gris claro y gris oscuro/negro. Las superficies son algo desiguales, $\mathrm{y}$ a veces hay pequeñas fracturas y agujeros a causa de la desaparición de algunos desengrasantes.

La pasta típica es negra, pero la gris es también frecuente, y en ocasiones, aparece la marrón-rojiza o anaranjada. Normalmente es más clara en su centro. Es bastante dura, pero desmenuzable y muy granulosa. Hay desengrasante abundante de cuarzo opaco-claro o marrón, redondeado (muy, fino-1/2 $\mathrm{mm}$, especialmente el tamaño pequeño). Se aprecian asimismo trozos o agrupaciones de pequeños cristales de un cuarzo casi transparente o marrón claro, y también existe un cuarzo de una mezcla transparente y blanca. Otros desengrasantes son o bien blandos, rojo-marrón (poco frecuente), o bien grises, duros, redondeados pero planos, tal vez de pizarra (fino- $2 / 3 \mathrm{~mm}$, frecuente), o bien negros vítreos, laminados de vidrio volcánico (?), que se aprecian especialmente en las superficies (muy finos- $2 \mathrm{~mm}$, frecuente). Para una descripción microscópica de la pasta, ver HAYES, $(1976,96)$ y FULFORD y PEACOCK $(1984,10-11)$.

* 44. El Sambo (Novelda).

45. El Charco. Yacimiento extensivo con muralla (?) y casas. Cerámica alto imperial. (comunicación personal con A. Poveda Navarro). ¿Una mansio de la Via Augusta?

46. Puente del Sambo. Cerámica romana (comunicación personal con A. Poveda Navarro).

47. El Negret / La Jaud. Cerámica romana (comunicación personal con A. Poveda Navarro). ¿Una mansio?

* 48. Las Agualejas. Villa. Cerámica alto-imperial (siglo VI).

49. El Puente. Cerámica romana. (Comunicación personal con A. Poveda Navarro).

50. C. Marina Española y adyacentes. Cerámica alto imperial, principalmente ánforas. ¿Villa y horno? (Comunicación personal con A. Poveda Navarro).

* 51. Arco Sempere. Villa. Cerámica alto imperial (quizá ARS del siglo VI). Excavación de A. Poveda Navarro.

* 52. Casa Colorá. ¿Villa? Cerámica alto imperial y tardorromana (ARS del siglo V).

* 53. El Monastil. Mansio Ello de la Via Augusta. Sede episcopal de Elo.

* 54. Cámara. Cerámica romana (siglo V).

55. Els Castellarets (Petrel).

No incluimos en el mapa «Els Castellarets» de Busot, por no saber dónde se localiza este yacimiento, aunque se encuentra cerca de Busot. Hay algunos otros yacimientos romanos que conocemos, pero que no incluimos por las mismas razones. En todo caso, esperamos que futuras prospecciones aumentarán masivamente esta lista de yacimientos. 


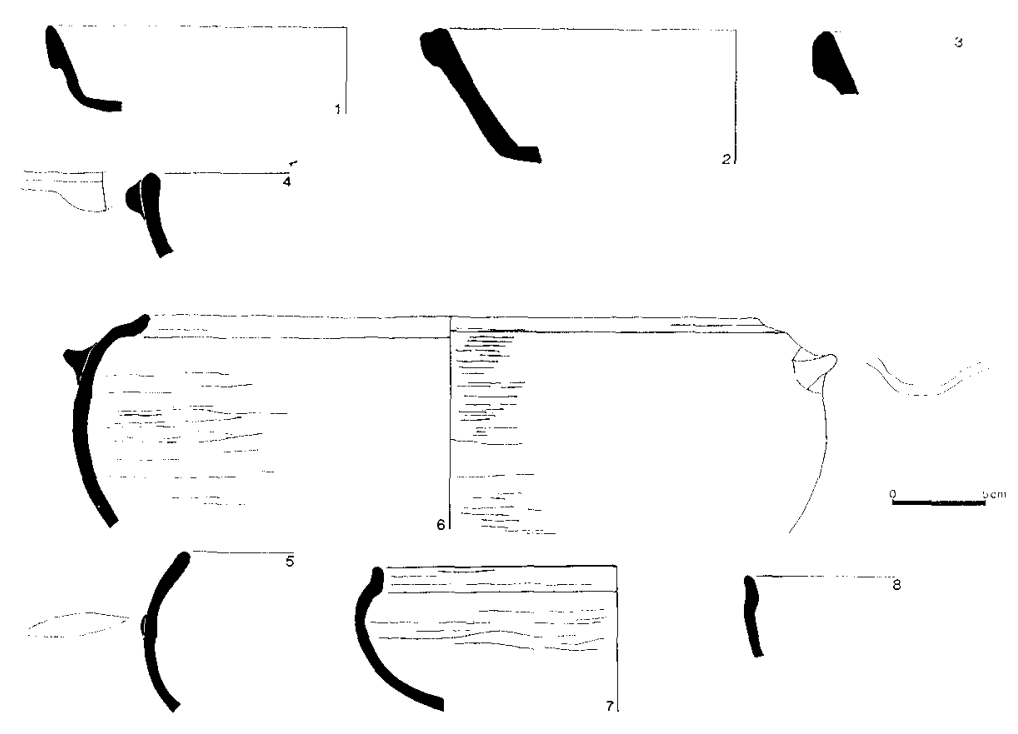

Fig. 2: 1. SPI/1043; 2. SPI/1076; 3. FC; 4. BEN/O-1575; 5. SPI/235; 6. BEN/O-1238; 7. BEN/O-1061;8. BEN/O-1127.

De las cinco formas en esta pasta en la tipología de Fulford, sólo tenemos ejemplares de una:

Forma 2.1 (fig. 2,6-8. FULFORD y PEACOCK, 1984, 159, 161, fig. 56, Form 8): Cazuela. Cuerpo hemisférico, base redondeada, hombro alto con un borde reentrante. Característico es el engrosamiento al interior y la moldura cóncava correspondiente al exterior, cerca del borde. Dos asas horizontales semilunares. Diámetro: $20-33 \mathrm{~cm}$. Es la forma más abundante de esta pasta en Cartago. Hay otro ejemplar de esta forma publicado por HAYES (1976, fig. 4. VII. 61). Fulford propone unas fechas de inicio en $475 / 500$, con amplio desarrollo ya en c. 525 , un floruit en c. 550, menor frecuencia hacia 575-600, y ya casi ausente en los contextos del siglo VII. Su distribución conocida se limita a Cartago, pero sabemos que hay ejemplares en Sicilia, al interior (conversación con J. Johns, Universidad de Newcastle).

En nuestra zona es abundante en el vertedero de Benalúa (1971), que confirma unas fechas entre los finales del siglo $\mathrm{V}$ y primera mitad del siglo VI. Un ejemplar atípico en Santa Pola (fig. 2,5) nos sugiere que existia una versión antigua de la forma en el siglo $\mathrm{V}$, probablemente antes de los finales del siglo. Hay unos ejemplares sueltos de la forma típica, en el Castillo de Santa Bárbara (Alicante), un enterramiento cerca del Tosal de Manises, La Alcudia, La Moleta (Elche), El Castellar (Elche), Castillo del Río (Aspe), El Sambo (Novelda) y El Monastil.

\section{Grupo 3.}

Carthage Late Roman Cooking Ware III (HAYES, 1976, 96) / Fulford Handmade Fabric 1.6-7 (FULFORD y PEACOCK, 1984, 12-13, 163, 165, 166 , figs. 58 y 59 ).

Cerámica a mano o a torno lento, de forma muy regular. Superficies bruñidas. Al interior, generalmente rojo-marrón pálido o marrón oscuro, en ocasiones marrón-grisáceo. Al exterior, rojo-marrón, marrón oscuro o negro. Especialmente característico son láminas abundantes de mica plateada (hasta $2 \mathrm{~mm}$ ) sobre las superficies.

La pasta puede ser bastante dura o algo blanda, granulosa, a veces finamente granulosa, y frecuentemente es laminosa, de color marrón-anaranjado, a veces negro o gris. Desengrasante de cuarzo algo marrón o casi transparente (muy fino-fino abundante, $0,5 \mathrm{~mm}$, poco frecuente), que en ocasiones parece fundir con la pasta, dándole un aspecto vítreo. También hay agrupaciones de pequeños cristales de cuarzo casi transparente y a veces casi blanco (0,5-1/2 mm, frecuencia moderada), trozos de ocre rojo y de cuarzo de tamaño mayor $(2 / 3 \mathrm{~mm}$, poco frecuente), láminas y fragmentos de mica plateada (hasta $0,5 \mathrm{~mm}$, abundante, 1-2 $\mathrm{mm}$, frecuencia moderada) y menos frecuentemente desgrasantes amarillentos pálidos de aspecto finamente esponjoso, de forma regular/rectangular. Para un análi- 
sis microscópico de la pasta, ver HAYES $(1976,96)$ y FULFORD y PEACOCK $(1984,12-13)$ : hay mica, hematites, feldespato, cuarzo, cuarzito y turmalina).

De las diez formas de esta pasta en la tipología de Fulford, sólo hemos encontrado dos:

Forma 3.1 (Fig. 3,9. FULFORD y PEACOCK, 1984, 163, 165, fig. 58, Form 20): Cuenco hemisférico, hombro alto, borde reentrante, engrosado al exterior. Dos asas horizontales, semilunares. Diámetro 21-31, generalmente 21-26. Sólo hemos encontrado ejemplares en el vertedero de Benalúa (1971: 23 bordes), en el Castillo de Santa Bárbara (un borde) y en la villa de La Ermita de Fontcalent (un borde). Fulford propone una fecha inicial c. 500, con un floruit antes de c. 535, siendo ya poco frecuente a partir de c. 550. También en Cartago, se han encontrado, en las excavaciones americanas, en niveles de los principios y mediados del siglo VI (HAYES, 1976, 58, 98, figs. 4 y 15, VII. 62 y 63, C. 27).

Forma 3.2 (Fig. 3,10-11. FULFORD y PEACOCK, 1984, 165, fig. 59, Form 27). Tapadera. Son notables la irregularidad del modelado del asa y el bruñido vertical sobre la pared exterior. Sólo conocemos tres bordes y cuatro asas del vertedero de Benalúa (1971). Según Fulford, el origen de este tipo de arcilla, algo micosa, ha de estar en Cerdeña, el sur de Italia o en Sicilia. Distribución: Túnez, Italia, Sicilia (es frecuente, según J. Johns, Universidad de Newcastle). Los ejemplares de Benalúa tienen unas fechas menos precisas, desde los finales del siglo $V$ hasta c. 550 , y sólo ayudan a confirmar las fechas ya propuestas.

\section{CERÁMICA LOCAL O REGIONAL}

\section{Grupo 4}

Aunque no descartemos la posibilidad de que sea una cerámica hecha a torno rápido, creemos que las superficies algo toscas y la irregularidad de los bordes, especialmente notable en el caso de la forma 4.2 , son indicaciones del uso del torno lento.

En el caso de la forma 4.1, las superficies son mates y alisadas, pero los desengrasantes son parcialmente visibles y, a veces, se ha saltado la capa exterior, mostrando la pasta debajo. En contraste, las superficies de la forma 4.2 están bruñidas, al interior y al exterior, o solamente la parte inferior del exterior. Superficie interior gris, marrón o marrón oscuro. El color es más oscuro al exterior, normal- mente un marrón oscuro, gris oscuro o negro. Es notable la presencia de fragmentos de mica dorada en las superficies.

La pasta es dura, desmenuzable y granulosa, con una fractura bastante irregular. El color típico es un marrón-rojizo o, a veces, gris oscuro. También hemos observado un "sandwich» de gris oscuro / marrón oscuro / gris, o marrón muy oscuro / negro $/$ marrón claro. En la pasta hay una mezcla bien distribuida de cuarzo algo amarillento, irregular, pero algo redondeado, que está formado por una agrupación de pequeños cristales de cuarzo blanco o casi transparente (muy fino-1 mm, abundante, $2-5 \mathrm{~mm}$, frecuencia moderada) y cuarzo blanco, anguloso (fino-1 mm, frecuencia moderada). También, está presente en algunos casos la calcita (?) blanca, rectangular. Hay láminas y fragmentos de mica dorada
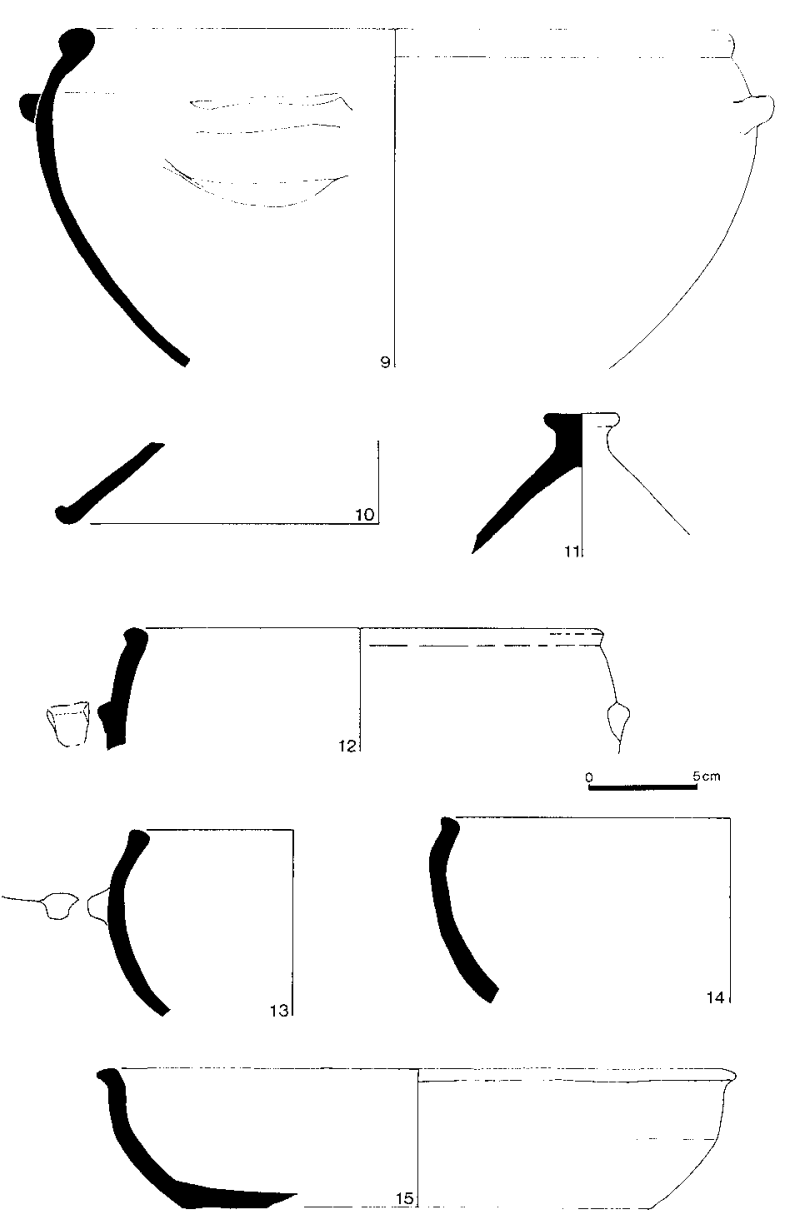

Fig. 3: 9. BEN/O-1404; 10. BEN/O-1636; 11. BEN/O-1430; 12. SP. Balsa $1.4 ; 13$. AL. $1980.18 ; 14$. SP. $\sin$ no. $6 ; 15$. SPI/936. 
(hasta $1 \mathrm{~mm}$, muy frecuente / abundante). Existen dos formas:

Forma 4.1 (fig. 3,12-13) Olla. Cuerpo globular, borde simple, engrosado al exterior, probablamente con una base plana. La moldura del borde es siempre algo irregular. En un caso se conserva un asamamelón. Al parecer, es la forma típica en esta pasta. Conocemos algunos ejemplares de esta forma en una pasta muy distinta, que interpretamos como productos contemporáneos de otro taller. Distribución: no lo encontramos en El Monastil, ni en las prospecciones en la villa de «Irles» (RAMOS, 1976, 212; Elche villa $n .^{\circ}$ 9: la cerámica fina se fecha en el siglo II-principios del siglo III, con un fragmento quizá del siglo V). Tampoco lo encontramos en las prospecciones en otra villa del Campo de Elche (RAMOS, 1976, 212, villa n.$^{\circ}$ 11: ARS de los siglos III-V). Es muy frecuente en la villa cerca del Tosal de Manises (ARS de los siglos II-IV), en la villa de La Ermita de Fontcalent, en las balsas de Santa Pola (ambos con cerámica fina desde el siglo I a.C hasta los finales del siglo V), y en Illici (La Alcudia). Hay unos pocos ejemplares en los dos vertederos de Benalúa. Es posiblemente la misma forma, y tal vez pasta, de los ejemplares de Santa Pola publicados por SÁNCHEZ FERNÁNDEZ (1983, 293, fig. 5, Tipo 2).

Forma 4.2 (fig. 3,14-15). Fuente. Tiene el mismo borde que la forma 4.1. Base plana. Bruñido parcial o sobre toda la pieza. No tenemos dudas de que esta forma es un producto modelado sin el torno rápido. Distribución: Es poco frecuente. Sólo conocemos unos pocos ejemplares de Santa Pola y del vertedero de Benalúa (1983). Es posible que haya dos versiones de esta forma en una pasta distinta procedentes de La Alcudia (Illici), que consideramos como productos de otro taller.

Es notable la ausencia de la cerámica del grupo 4 de las villas de la zona de Villena, Sax, Elda, y las que hemos prospectado en El Campo de Elche. Sospechamos que o bien se trata de una cerámica local de la zona de Alicante o bien es una importación regional, quizá de Murcia como el grupo 5, con una distribución costera. Creemos que no tiene fechas del siglo $\mathrm{V}$ en adelante, por su ausencia en los yacimientos de altura (notablemente en el Castillo de Santa Bárbara de Alicante, cerca del mar) $y$ por su poca frecuencia en el material de los vertederos de Benalúa (Alicante). Una fecha posible es la de los siglos II-IV, pero la ausencia de este tipo en el material del Tossal de Manises, cuya cerámica fina más tardía es de c. 230 , nos lleva a pensar que el grupo 4 se puede fechar desde el segundo cuarto del siglo III hasta los finales del siglo IV - principios del siglo $\mathrm{V}$ (por los ejemplares residuales de Benalúa).

\section{Grupo 5}

Cerámica modelada a mano. Paredes, cuerpo y bordes irregulares. Bruñida con trazos más o menos horizontales. Característica es la abundancia de fragmentos de mica dorada sobre las superficies (hasta $0,5 \mathrm{~mm}$, siendo menos frecuente los inferiores a $2 \mathrm{~mm}$ ). Las superficies son de color marrónrojizo, marrón oscuro o negro, y la pasta es de estos mismos colores, frecuentemente con un centro más oscuro (marrón-negro). Es muy granulosa, dura, pero de fractura desmenuzable y bastante irregular. Característicos son los desengrasantes de cuarzo (fino $1 \mathrm{~mm}$, abundante, $2 \mathrm{~mm}$, moderado) bien mezclados, que se destacan contra la pasta oscura. En este cuarzo podemos distinguir un tipo formado por agrupaciones de cristales transparente y otro con fractura angulosa, formando materia blanca y transparente (como las pastas de los grupos 2 y 4). No podemos observar otra clase de desengrasante (como cal u ocre, por ejemplo). Debemos señalar que en El Monastil hay dos fragmentos con pastas que son variantes respecto al material abundante con la pasta «clásica» de este grupo. Existen dos formas:

Forma 5.1 (Fig. 4, 16-19) ligeramente reentrante. Cuenco hemisférico, con borde grande ( $\varnothing$ 21-24) y otro pequeño ( $\varnothing$ 17-18). En algunos casos se conservan fragmentos de asas horizontales, probablemente de forma semilunar. Es la forma más frecuente en esta pasta. Distribución: es frecuente en El Monastil y en La Moleta (Elche). Se ha encontrado en casi todos los otros yacimientos tardorromanos de altura (Castillo de Santa Bárbara, Castillo del Río (Aspe), El Sambo, Els Castellarets (Petrel). También hay ejemplares en La AlcudiaIllici, las balsas de Santa Pola, los vertederos de Benalúa y algunos yacimientos en llano como la villa de Candela (Villena) (SOLER GARCIA, 1967), o la villa de Vizcarra n. ${ }^{\circ} 2$ (Elche. RAMOS FERNÁN$\mathrm{DEZ}, 1976,211)$. Lo encontramos igualmente más lejos, en los yacimientos de altura de Cabeza de las Roenas/Bigastrum (Cehegín, Murcia) y El Castellar (Alcoy), y en una villa de la zona de Onil (Museo de Villena. Material de prospección de L. Abad Casal). 
Forma 5.2 (Fig. 4, 20-22) Fuente, de base más o menos plana, pared curva simple que termina en un borde ligeramente reentrante como la forma 5.1. Diámetros 19-35 cm. Distribución: es bastante abundante en El Monastil, siendo más frecuente que la forma 5.1. en el vertedero de Benalúa (1971: 6 ejemplares). Lo encontramos también en La Alcudia (Illici), las Balsas de Santa Pola (?), La Moleta (Elche), Castillo del Río (Aspe), El Sambo y, un ejemplar, en Los Baños de la Reina (Calpe).

En cuanto a las fechas de la cerámica, está claro que es una forma típica de los yacimientos donde hay abundancia de ARS del siglo V (notablemente El Monastil y La Moleta, donde parece ser casi la única cerámica de cocina en cantidades que sugieren su contemporaneidad con la cerámica fina abundante del siglo V). Otro argumento que confirma la datación en el siglo $\mathrm{V}$ es la menor presencia de esta cerámica en los vertederos de Benalúa (bastante escasa si se compara con la cerámica del grupo 7), lo que sugiere su contemporaneidad con el poco ARS de la primera mitad del siglo $\mathrm{V}$ o quizá con el ARS de los finales de este siglo (ver REYNOLDS, en prensa). También es importante la aparición de cerámica de este grupo en algunas villas que no se pueden fechar después del siglo $\mathrm{V}$.

Tiene una distribución amplia a lo largo del Vinalopó, hasta la costa, pero desconocemos la dirección de este tráfico; la existencia de ejemplares en lugares tan alejados como Calpe podría indicar un transporte marítimo, pero parece más claro que la línea de comercio fuera desde el norte de Murcia, entrando por el valle al norte de Elda/El Monatil, hasta llegar al mar. Creemos por tanto que se trata de una cerámica procedente del comercio a partir de un único centro o varios cercanos entre sí (vid. infra). La presencia de gran cantidad de mica dorada en la pasta, demasiado abundante para ser fortuita, nos lleva a buscar el centro de producción en un área situada al oeste de Jumilla, donde existen dos grandes concentraciones de este mineral (hoja $72 \mathrm{del}$ Mapa Geológico de España, Instituto Geológico y Minero de España), en tal cantidad que localmente se llamó a esta mica dorada «jumilleta» (información procedente de A. Poveda y del equipo del laboratorio del Departamento de Geografía de la Universidad de Alicante). Es posible que haya otro yacimiento de dicho mineral en Alicante, pese a lo cual nos inclinamos a dar un origen murciano a estas cerámicas por ser su pasta una de las más típicas de la cerámica del bronce de la zona de Murcia (véase

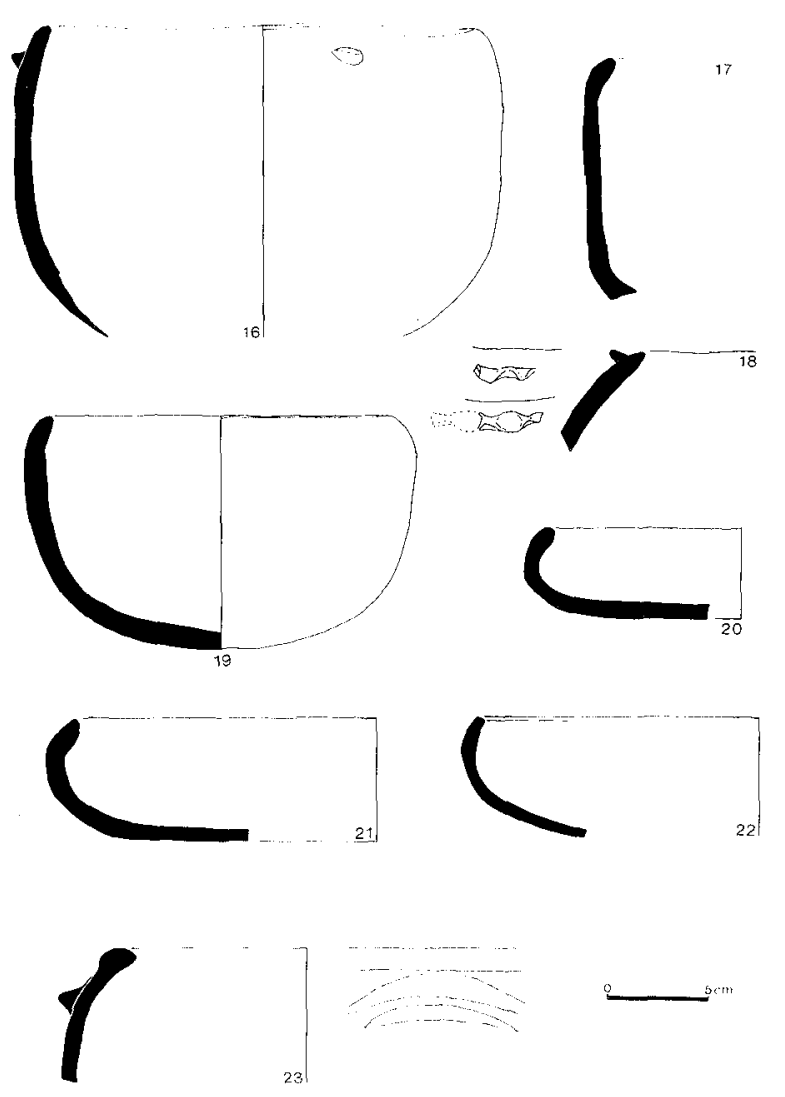

Fig. 4: 16. EM 949; 17. EM 960; 18. EM 970; 19. EM 974; 20. EM 938; 21. EM 939; 22. EM 940; 23. EM 976.

la cerámica del Cabezo Negro, Lorca, en el Museo Provincial de Murcia), mientras que no la encontramos en la cerámica del bronce de Alicante.

El carácter de importación murciana de estas pastas se apoya en el hecho de no ser la única con esta procedencia, pues ya hemos sugerido que la cerámica del grupo 4 puede tener idéntico origen. Además hay que señalar la existencia de un grupo de formas hechas a torno rápido, con una pasta muy llamativa por sus desengrasantes de mica plateada, que también encontramos en la cerámica del Bronce en Murcia. Es más, esta cerámica hecha a torno es contemporánea de la cerámica del grupo 5 y se encuentra en los mismos yacimientos.

\section{Grupo 6}

Cerámica modelada a mano o a torno lento. Superficies bruñidas al interior y exterior, o sólo al exterior, debajo del borde. Superficies de color marrón, o marrón al interior y negro al exterior. Es 
frecuente ver la prominencia de algunos desengrasantes en las superficies. La pasta no es distintiva. Los pocos ejemplares que hemos podido examinar tienen una pasta marrón, uno de ellos con una banda central gris. Tiene una fractura algo dura, desmenuzable y muy granulosa. Es muy característico un desengrasante formado por trozos de una piedra dura, con facetas, rojo-marrón-algo rosado/gris púrpura pálido ( $\varnothing, 5-2 \mathrm{~mm}$, moderada frecuencia). Hay algunos fragmentos de pizarra (?) gris, fracturable a mano. La cal es poco frecuente (fino- 1,5 $\mathrm{mm}$ ) y también hay cuarzo semi-translúcido (fino$1 \mathrm{~mm}$ ), frecuente $y$, de vez en cuando, algún trozo mayor $(3 \mathrm{~mm})$.

Forma 6.1 (Fig. 4, 23) Cuenco. Cuerpo probablemente hemiesférico con una base redondeada. Hombros reentrantes con borde engrosado al exterior. Presenta dos asas horizontales semilunares. Diámetros conocidos de 17 y $22 \mathrm{~cm}$. Es una forma muy similar al 3.1, pero no se pueden confundir porque tienen pastas muy diferentes. Distribución: conocemos pocos ejemplares, en El Monastil ( 2 bordes), y en El Sambo (4 bordes).

Forma 6.2 (sin dibujar). Olla. Probablemente realizada en este tipo de pasta. Base plana, cuello estrangulado, borde un poco exvasado, irregular (como la forma 7.7 exactamente, o la forma 8.1). Distribución: sólo conocemos un ejemplar en el Museo de Novelda, de El.Sambo. Era imposible examinar la pasta y lo incluimos en el grupo 6, con reservas.

La poca frecuencia de cerámica de este grupo puede indicar que se trata de una importación regional, pero, en realidad, no tenemos datos suficientes para decidirnos al respecto. Tampoco descartamos la posibilidad de que sea una Fulford Handmade Ware 1.9, donde hay también una forma muy parecida al 3.1 , con una pasta muy similar a la nuestra, según se desprende de la descripción (FULFORD y PEACOCK, 1984, 13, 166, fig. 59, Form. 32).

En cuanto a la datación de la cerámica, contamos con pocos elementos de juicio. Creemos por lo menos que es cerámica tardorromana, y no de época islámica, como sí lo es parte del conjunto cerámico de El Sambo (ver AZUAR, 1983, 378, e infra). Los ejemplares del Monastil podrían indicar unas fechas en el siglo V, pero la semejanza con la forma 3.1, que no creemos simplemente fortuita, nos sugiere una fecha posterior, situada en la primera mitad del siglo VI, fecha propuesta también para la forma Fulford 32 (FULFORD y PEACOCK, 1984, 166). Si la identificación del ejemplar de la forma 6.2 es correcta, la existencia de una forma paralela en la pasta 7 también indicaría una fecha a partir del siglo VI.

\section{Grupo 7}

Cerámica modelada a mano. En el caso de la forma 7.6, las marcas de estera bajo la base son indicio probable de que esta forma con base plana fue modelada girando sobre este soporte. En esta y la forma 7.4 se pueden apreciar las impresiones de los dedos al formar la pieza. Los bordes son algo irregulares y en muchos casos son biselados, con un perfil cuadrado. Es una cerámica muy tosca y, aunque las superficies son alisadas a mano, los desengrasantes de la pasta son claramente distinguibles. Las superficies interiores suelen ser de color rojo-marrón pálido o marrón anaranjado. Los exteriores son más oscuros, de color marrón-rojizo oscuro, marrón oscuro, o marrón negro.
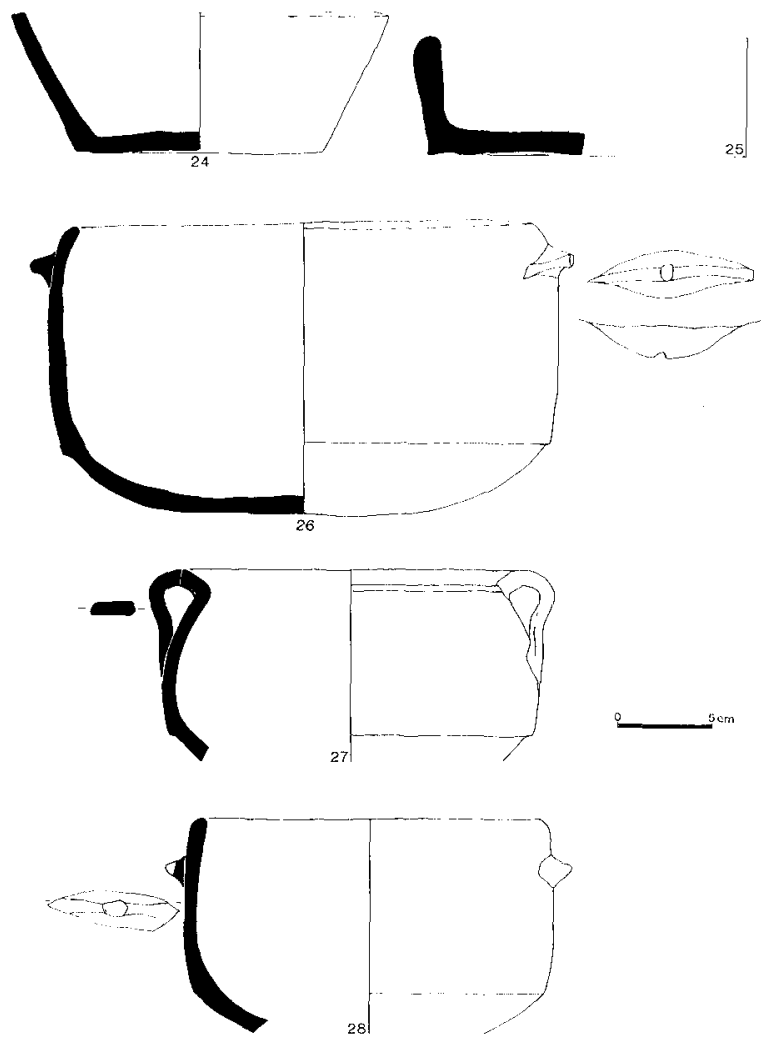

Fig. 5: 24. AL 257;25. AL 214;26. FC 1295;27. AL 205; 28. AL 207. 
La pasta es muy tosca, granulosa, con fractura irregular y desmenuzable. Hay un desengrasante abunante de un tipo de pizarra (?) (como en la pasta del grupo 6) algo redondeado pero plano, de grano fino, algo brillante, laminado, de varios colores (rojo púrpura pálido, crema, amarillento, gris y gris oscuro, fino $3 / 4 \mathrm{~mm}$ ). Hay también cuarzo semianguloso y cuarzo formado por agrupaciones de pequeños cristales ( $1 \mathrm{~mm}$, moderado). Hay cal (fino 0,5: frecuente; $1 / 2 \mathrm{~mm}$ poco frecuente) y trozos de ocre, rojo-marrón (hasta $2 \mathrm{~mm}$, poco frecuente). Las formas son:

Forma 7.1 (Fig. 5, 24) Escudilla. Base plana, paredes rectas e inclinadas. Diámetro $18,8 \mathrm{~cm}$. Sólo conocemos este ejemplar de La Alcudia/Illici.

Forma 7.2 (Fig. 5, 25) Fuente. Pared vertical, base plana. Diámetro $35 \mathrm{~cm}$. color negro sobre la pared exterior y parte de la base exterior. Sólo conocemos este ejemplar de La Alcudia/Illici.

Forma 7.3 (Fig. 5, 26) Cuenco. Pared vertical, de tendencia convexa, base redondeada, con una carena marcada por una moldura en la unión con el cuerpo, como la forma 7.4. Dos asas horizontales semilunares, decoradas con una impresión. Diámetro $24 \mathrm{~cm}$. Las superficies exteriores, de color marrón oscuro negro, son indicio del uso de esta forma para cocinar sobre el hogar. Sólo conocemos este ejemplar de la villa de La Ermita de Fontcalent. Hay un fragmento de pared carenada de esta forma, o de la forma 7.4, procedente de El Monastil.

Forma 7.4 (Fig. 5, 27) Cuenco. Dos asas rectangulares con implantación en el borde exvasado y en el hombro. Al igual que la forma 7.3 presenta una marcada carena que separa la base convexa de las paredes. Impresiones digitales al interior. Diámetro $28.8 \mathrm{~cm}$. Sólo conocemos dos ejemplares de $\mathrm{La}$ Alcudia/Illici.

Forma 7.5 (fig. 5,28. Fig. 6,29): Cuenco para cocinar. Pared recta de tendencia convexa, que termina en un borde simple redondeado o algo aplanado. Base redondeada con marcada carena, pero sin la moldura de la forma 7.3. Tiene dos asas horizontales semilunares. Diámetros de $18-25 \mathrm{~cm}$. Es frecuente en La Alcudia, pero no conocemos ejemplares en otros yacimientos.

Forma 7.6 (fig. 6,30-32. Fig. 7,33,34): Vasija para provisiones (?). Paredes rectas, verticales o ligeramente exvasadas, borde normalmente plano. Base plana, con marcas de estera en algunos casos. Impresiones digitales al interior. Diámetro de 18.5-31, normalmente 18.5-22. Dos asas horizontales semiluna- res. Un ejemplar de La Alcudia tiene decoración incisa al exterior (fig. 6,31. RAMOS FERNÁNDEZ, 1983, 156, A-6). La falta de manchas negras en las paredes y especialmente en la base en la mayoría de casos, nos sugiere que no era un recipiente para cocinar sobre el hogar. Incluimos aquí dos variantes, probablemente de esta forma (fig. 7,33: $\varnothing 21$, de la Alcudia y fig. 7,34: $\varnothing 35$, de La Ermita de Fontcalent). Distribución: Es la forma más difundida del grupo 7, y en casi todos los casos es la única forma del grupo presente. Lo encontramos en Benalúa (Alicante), la villa de La Ermita de Fontcalent, La Alcudia / Illici, La Moleta (Elche), El Castellar (Elche), Castillo del Río (Aspe), la necrópolis de Vistalegre (Aspe), El Sambo, Els Castellarets (Petrel) y El Monastil.

Forma 7.7 (fig. 7,35-38): Vasija para provisiones u olla. Base plana, ligeramente cóncava, cuerpo esférico, cuello estrangulado y un borde un poco exvasado, plano y algo irregular. Diámetros conocidos de 9 y c. $12 \mathrm{~cm}$. Interior rojo-marrón algo oscuro, exterior marrón oscuro / negro. Es posible que se
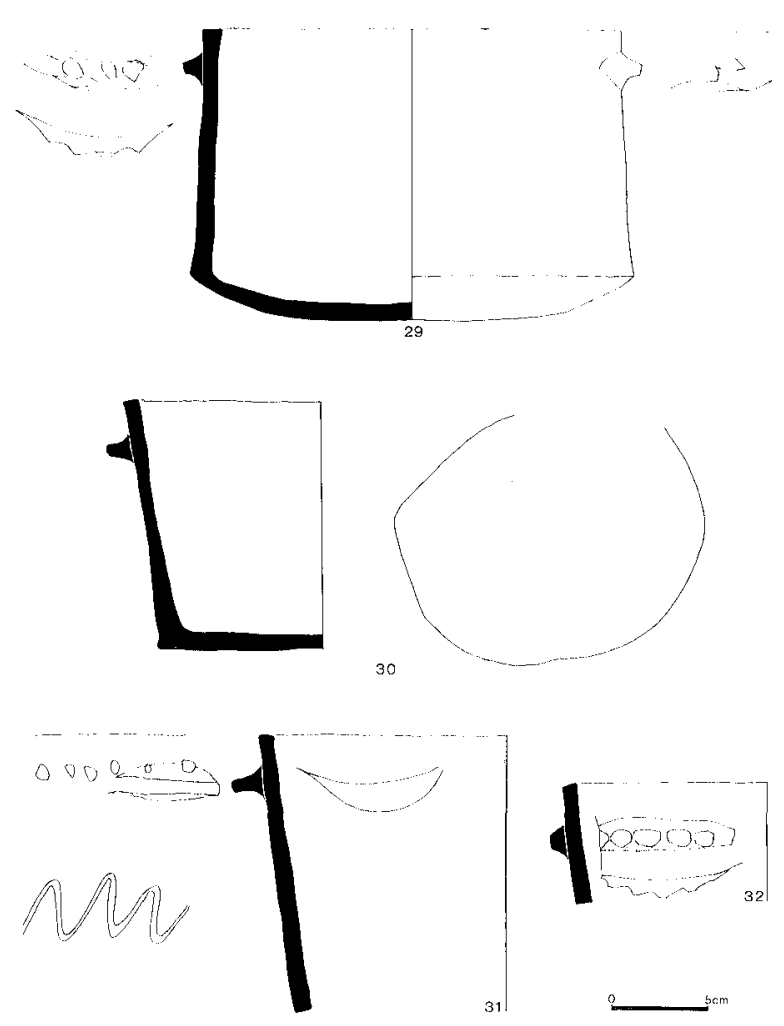

Fig. 6: 29. AL 258; 30. AL 259; 31. AL 1981.84; 32. ALT. sin proc, 3 . 


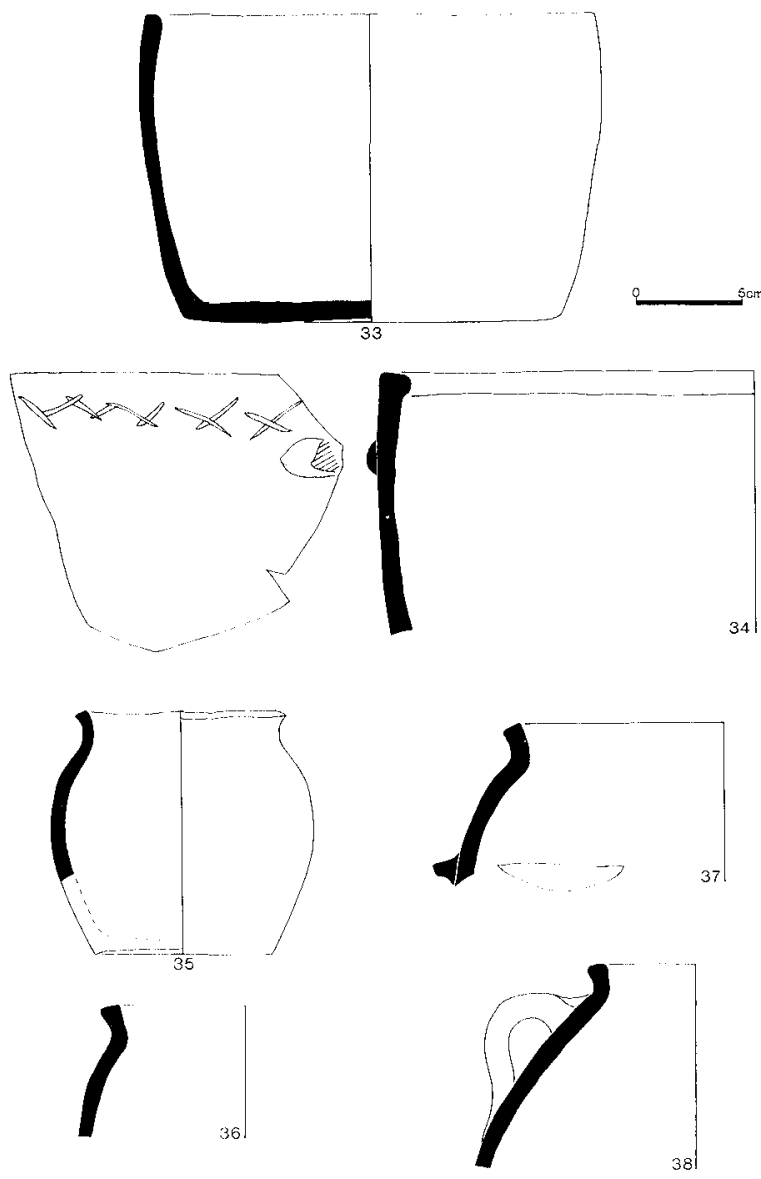

Fig. 7: 33. AL 260; 34. FC 1299; 35. AL 258; 36. AL 1981.43; 37. ALT. sin proc. 4; 38. FC 1296.

usara para cocinar. Sólo conocemos dos ejemplares de La Alcudia / Illici (fig. 7,35-36). En contraste, es la forma típica de la cerámica del grupo 8 (Forma 8.1). Hay una forma muy similar con la pasta del grupo 6 (Forma 6.1). Incluimos bajo esta forma por el momento dos piezas de forma similar, pero de tamaño mayor, una con asa horizontal semilunar (fig. 7,37: diámetro 19.4, sin procedencia, pero probablemente de La Alcudia) y otra con asa rectangular vertical (fig. 7,38: diámetro $4.3 \mathrm{~cm}$, de la villa de La Ermita de Fontcalent).

Forma 7.8 (fig. 8,39-42): Tapadera plana con una o dos asas rectangulares. Diámetro 21-37, especialmente 21-25. Distribución: es abundante en La Alcudia / Illici, donde lo encontramos siempre con decoración impresa e incisa muy variada. De otros yacimientos sólo conocemos dos ejemplares sin decoración, uno de El Castellar (Elche) y otro del vertedero de Benalúa (1971).
Forma 7.9 (fig. 8,43): Jarra, con un asa rectangular, base plana, de una técnica similar a la de la forma 7.7 y algunos ejemplares de la forma 7.6, con el ángulo bien marcado. Sólo conocemos dos ejemplares, uno de La Alcudia / Illici, y otro idéntico, sin procedencia, pero probablemente del mismo yacimiento (Museo del Palacio de Altamira, Elche).

Forma 7.10 (fig. 8,44-45): Anforilla con una o dos asas rectangulares, cuello alto, vertical y borde plano. Diámetros 5.6 y $8 \mathrm{~cm}$. Es parecida a la forma típica de las ánforas árabes de la zona (ver fig. 12,79, de época islámica del Castillo del Río, Aspe). Sólo conocemos los ejemplares de La Alcudia que ilustramos, y un asa rectangular de esta forma o quizá de la forma 7.9, de El Monastil. También hay un ejemplar con la pasta del grupo 9 (Forma 9.6). El hecho de que La Alcudia sea el yacimiento donde aparece un mayor número de formas $(7.1,7.2,7.4$, $7.5,7.7,7.9(?), 7.10(?)$, y el único en que algunas de estas presentan decoración ( 7.6 y 7.8 , esta última con una gran variedad decorativa), nos inclina a pensar que el centro de producción de este tipo de cerá-
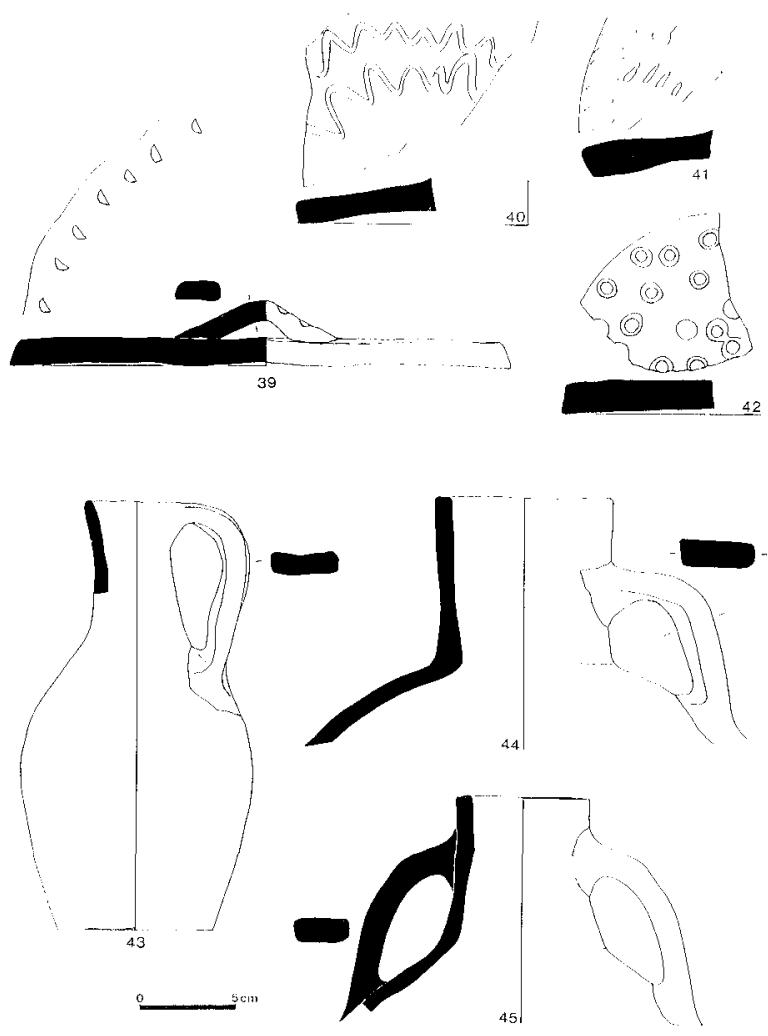

Fig. 8: 39. AL 263; 40. AL 269; 41. AL 281; 42. AL 271; 43. ALT sin proc.; 44. AL.ALT. 23; 45. AL 184. 
mica estuviese en La Alcudia (Illici), y más si tenemos en cuenta que en el resto de los yacimientos aparece una única forma (7.6).

Otro elemento claro es la datación de la cerámica a partir de principios del siglo VI. Este material está ausente en el conjunto cerámico de las balsas de Santa Pola y en la cerámica de las antiguas excavaciones de El Monastil (con la excepción de una pieza. Ver 7.10). También notable su ausencia, hasta el momento en los conjuntos de prospección de las villas romanas con ARS del siglo $\mathrm{V}$, pero no más tardíos, donde, además, en algunos casos, hemos identificado ejemplares de la cerámica del grupo 5 . En contraste, es un elemento importante en la cerámica del vertedero de Benalúa (1971) donde acompaña a la cerámica fina de la primera mitad del siglo VI.

Más problemática es la posibilidad de la perduración de esta cerámica en fechas más tardías. Preferimos dejar esta cuestión para más tarde, una vez estudiada la cerámica de los grupos 8 y 9 .

\section{Grupo 8.}

Cerámica modelada a mano. Las superficies son gris claro o gris, a veces con un tono marrón amarillento, y alisadas a mano, aunque se aprecian los desengrasantes en la superficie. La pasta es gris oscuro-negro, dura, con una fractura laminosa e irregular. En la pasta hay desengrasante blanco, anguloso, de grano fino no muy duro (quizá calcita), abundante y bien mezclado (fino- $3 \mathrm{~mm}$ ). También notable es un desengrasante poco frecuente de cuarzo (?) casi blanco, con fractura regular, y finamente laminado. Otra variante de esta pasta tiene las superficies más porosas, donde se aprecian aún mejor los desengrasantes de la pasta. En este caso predominan los desengrasantes de cuarzo blanco. Existen las mismas formas en ambas variantes de la pasta. El modelado es bastante tosco, con bordes y paredes irregulares:

Forma 8.1 (fig. 9,46-51): Olla, o menos probablemente, vasija para provisiones. Base posiblemente plana, cuerpo esférico, cuello estrangulado, borde un poco exvasado e irregular. Diámetro c. 16 $\mathrm{cm}$. Existe la misma forma en la pasta del grupo 7 (forma 7.7), siendo la más frecuente en el grupo 8. Incluimos bajo esta forma, por el momento, una versión de tamaño mayor (fig. 9,48-49. Diámetro $26 \mathrm{~cm}$ ).
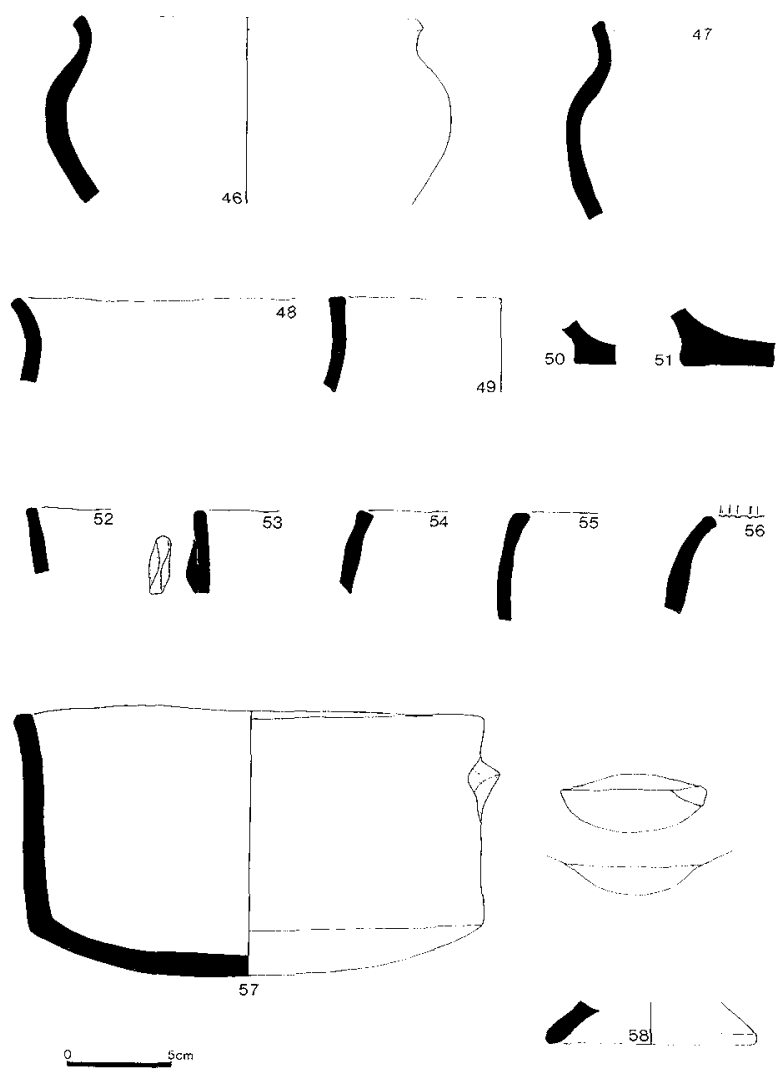

Fig. 9: 46, FC; 47. FC; 48. FC E4-36; 49. FC E4-31; 50. FC E437?; 51. FC E4-76; 52. FC E4-24; 53. FC E4-99; 54. FC E4-9; 55. FC D3-44; 56. FC E4-75; 57. FC 1298; 58. FC H4-8.

Forma 8.2 (fig. 9,52-53): Olla o vasija para provisiones. Base probablemente plana, pared recta. Un ejemplar tiene un asa pequeña vertical. Forma tal vez como la 7.6.

Forma 8.3 (fig. 9,54-56): Cuenco (?), con borde / pared reentrante. Incluimos bajo esta forma al menos por el momento, un ejemplar con decoración incisa sobre el borde (fig. 9.,56). Compárenla con las formas 7.3 y 7.5 .

Forma 8.4 (fig. 9,57): Pared recta un poco exvasada, carena en el tránsito a la base redondeada. Dos asas horizontales semilunares. Diámetro $22 \mathrm{~cm}$. Hay una clara relación con las formas 7.3 y 7.5. Sólo conocemos este ejemplar. No pudimos examinar la pasta, que también podría ser del grupo 7 .

Forma 8.5 (fig. 9,58): Tapadera (?) Diámetro $9 / 10 \mathrm{~cm}$. Cerámica de este grupo sólo la hemos encontrado en la villa de La Ermita de Fontcalent, donde también aparece cerámica del grupo 7 (for- 
mas 7.3 y 7.6). La fecha de esta cerámica ha de ser posterior a la del ARS más tardío (siglo V) porque aparece en este yacimiento junto con la del grupo 7 con la que está muy relacionada. Creemos que puede datarse en una época posterior a las últimas importaciones de ARS, a partir de c. 575 y quizás también dentro del siglo VII, pero sin llegar a formar parte de los conjuntos de época islámica.

\section{Grupo 9.}

Cerámica hecha a mano. La cerámica de este grupo se limita a un conjunto recogido en superficie en el yacimiento de Arneva (Sierra de Cristo, Orihuela). En sus características de pasta y modelado es indistinguible macroscópicamente de la cerámica del grupo 7, pero en cuanto a las formas presenta diferencias importantes que nos han inclinado a considerarla como producto de un centro distinto, aunque contemporáneo. Hablaremos enseguida de los problemas de su datación después de haber presentado las formas.

Forma 9.1 (fig. 10,59): Cuenco (?) Asa horizontal semilunar. Decoración ondulada incisa al exterior por encima del asa. Diámetro $24 \mathrm{~cm}$. Un posible paralelo es una pieza que consideramos de época islámica procedente de La Alcudia (fig. 11,75).

Forma 9.2 (fig. 10,60): Vasija para provisiones (?) Pared recta exvasada. Diámetro $20 \mathrm{~cm}$.

Forma 9.3 (fig. 10,61-62): Vasija para provisiones (?) Pared recta, base plana. Asas horizontales semilunares. Diámetro $23 \mathrm{~cm}$. (Forma idéntica al 7.6). Incluimos bajo esta forma un ejemplar con pared más inclinada y asa inclinada marcadamente hacia arriba (diámetro $31 \mathrm{~cm}$ ). (fig. 10,62).

Forma 9.4 (fig. 10,63): Olla o cuenco. Cuello abierto, pero un poco estrangulado, hombro alto. Asa horizontal semilunar. Decoración por encima del asa, semejante a la forma 9.1. Diámetro c. 19 $\mathrm{cm}$.

Forma 9.5 (fig. 10,64-67): Vasija tal vez para guardar provisiones. Cuerpo esférico, borde alto, algo exvasado. Hay dos tamaños, uno grande (nos. $64-65$, diámetros 9 y $20 \mathrm{~cm}$ ) y otro pequeño (nos. 66-67, diámetros 12 y $16 \mathrm{~cm}$ ). Es la forma más frecuente en el conjunto. Compárenla con la forma 7.7.

Forma 9.6 (fig. 10,68): Anforilla. Sólo tenemos un fragmento de cuello y asa. Compárenla con la forma 7.10 .

En el grupo 9 hay dos formas idénticas a las formas 7.5 y 7.9. Las demás muestran unas diferen-
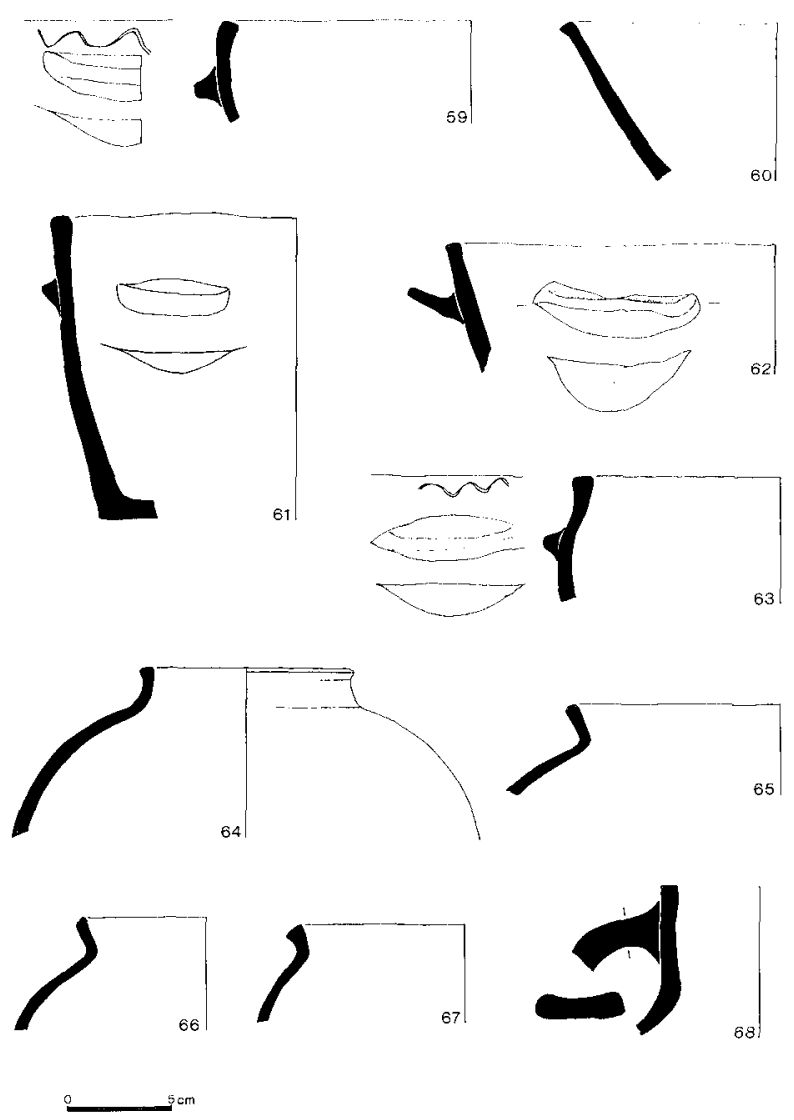

Fig. 10: 59. ARN 6; 60. ARN 2;61. ARN 1;62. ARN 3;63. ARN 5; 64. ARN 8; 65. ARN 10;66. ARN 9; 67. ARN 7; 68. ARN 12.

cias notables con la cerámica típica del grupo 7: aunque muy similar a los de la forma 7.7 , las vasijas de la forma 9.5 son más grandes, más esféricas, de una mejor técnica, y más abundantes que los pocos ejemplares que conocemos en la cerámica del grupo 7; la forma de escudilla con paredes inclinadas en el grupo 7 (forma 7.1) no es muy comparable con la forma 9.2 ; y el asa del ejemplar $n .{ }^{\circ} 62$ (fig. 10) no tiene paralelo en la cerámica del grupo 7 ; tampoco encontramos las formas 9.1 y 9.4 en el grupo 7 y la decoración de ambos ejemplares, con una línea incisa ondulada, que se puede considerar como una posible característica de la cerámica de Arneva, lo tenemos sobre un solo ejemplar de la forma 7.6 y sobre algunos ejemplares de la tapadera forma 7.7 (fig. 8,40).

Como ya hemos comentado, queda claro que esta cerámica, aunque procedente de un centro distinto, es contemporánea de la cerámica del grupo 


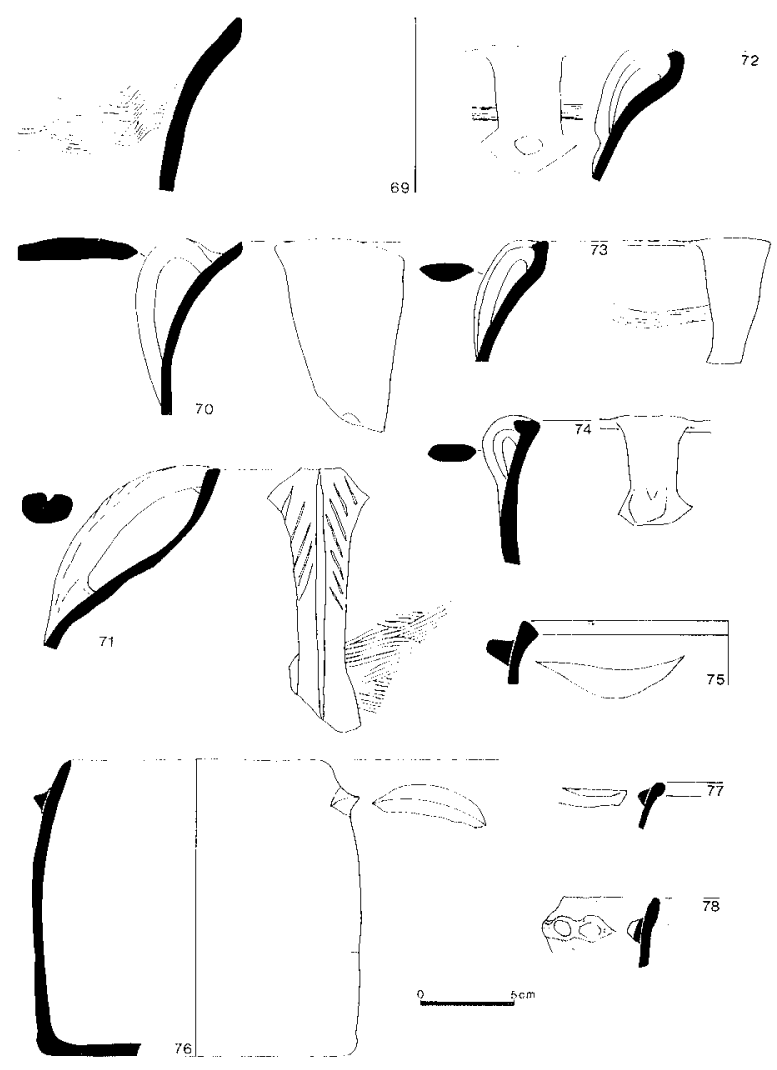

Fig. 11: 69. CAST.ALT 7; 70. AL.ALT 41; 71. ALT sin proc.; 72. CAST DE BUSOT; 73. AL ALT. 34; 74. AL ALT 32; 75. AL ALT 35; 76. CASTELLAR (Alcoy); 77. CAST DE BUSOT; 78. CAST DE BUSOT.

7 , en parte por la pasta idéntica, en parte por la existencia de tres formas casi iguales $(9.3,9.5,9.6)$. Sin embargo, la fecha de contemporaneidad es algo que no podemos definir con seguridad, entrando de esta forma en la problemática de la fecha del grupo 7 .

En primer lugar, al igual que la cerámica del grupo 8, sospechamos que la cerámica de Arneva se fecha en una época posterior a las importaciones de ARS, a partir de c. 575. Pero es más, pensamos que quizá sea ya un producto de época islámica, con-

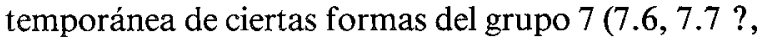
7.10 ?) en yacimientos del siglo VIII. Otra posibilidad es que estas formas del grupo 7, y las del grupo 9 sean contemporáneas de la serie de formas hechas a mano / a torno lento que fechamos hacia el siglo IX (vid. infra.); ver especialmente la similitud de la forma 9.1 con la pieza $n .^{\circ} 75$ (fig. 11), que inventariamos como ejemplar único, en la colección de $\mathrm{P}$. Ibarra (Museo del Palacio de Altamira, Elche), junto con otros ejemplares también de La Alcudia y de esta colección que clasificamos como islámi$\cos$ (fig. 11,70,73,74).

Aunque en realidad pensamos que la cerámica del grupo 9 es de época islámica, lo hemos incluido en nuestro esquema de los grupos de cerámica tardorromana por su clara relación con la cerámica del grupo 7.

\section{CONCLUSIONES}

La lectura del trabajo de FULFORD y PEACOCK (1984) sobre la cerámica de las excavaciones británicas en Cartago nos muestra la variedad y gran volumen de cerámica modelada a mano o a torno lento de importación en esta metrópolis durante la época tardorromana, que constituye entre un 5 y un $20 \%$ del total de la cerámica de cocina (FULFORD y PEACOCK, 1984, 166-167). El resto del conjunto de cerámica de cocina contemporáneo está compuesto por cerámica hecha a torno, ya sea de importación o local y regional.

El estudio de la cerámica tardorromana de la región alicantina nos ha mostrado una distribución cerámica muy similar. No sólo hay coexistencia, en conjuntos cerámicos contemporáneos, de productos hechos a torno y a mano, sino que también existen tres de las diez clases de cerámica modelada a mano o a torno lento de importación de Cartago. En cuanto a los distintos grupos de cerámica local y regional, hay formas y técnicas de modelado (sobre todo las asas horizontales de forma semilunar) tan similares entre si y con las de las formas de importación, que se puede hablar de una tradición mediterránea común para esta clase de cerámica durante esta época.

La estructura de la producción y el comercio de la cerámica modelada a mano y a torno lento ha sido recientemente objeto de estudio de PEACOCK (1982). Con el uso de paralelos etnográficos, nos ofrece modelos muy útiles para la interpretación de la organización y comercio de este tipo de cerámica en la época romana. Antes de hablar de la distribución y significado de la cerámica en nuestra zona, creemos que es conveniente repasar algunos de los puntos de su trabajo.

La cerámica hecha a mano o a torno lento es un componente típico de muchos conjuntos cerámicos modernos (PEACOCK, 1982, 75) y según este autor hay dos niveles de producción. 
El primer nivel, el más básico, es la producción casera («Household production»), ilustrado por la producción cerámica de los bereberes en el norte de África (PEACOCK, 1982, 13-16). La cerámica la realizan a mano las mujeres durante su tiempo libre y normalmente está destinado sólo al uso en la propia casa; lo cuecen ellas mismas simplemente sobre el fuego abierto; no participan los hombres, no hay técnicas avanzadas para la producción de esta cerámica como el torno y el horno, no se dedica una temporada específica a este trabajo, ni hay un intento de vender la cerámica fuera del asentamiento, ya que este tipo de producción no forma parte de la economía de la sociedad.

El segundo nivel de producción diferenciado por Peacock es la industria casera ( Household industry») (PEACOCK, 1982, 17-25). Se trata de una cerámica hecha también por las mujeres a mano o, en muchos casos, a torno lento, pero en la mayoría de casos con la participación de los hombres en la cocción de la cerámica al aire libre o en hornos. Es trabajo propio de una temporada específica, normalmente durante seis meses al año, y la diferencia principal es que un porcentaje de esta cerámica está destinado a la venta fuera de la población, aunque normalmente limitada al mercado regional. En la mayoría de los casos, son las mujeres las que se dedican a la venta, a pie y con el uso de burros para transportar las mercancías. Es típica la venta de la cerámica en ferias regionales, en un radio de hasta unos $60 \mathrm{Km}$, pero conocemos casos en que la cerámica puede alcanzar un mayor radio de dispersión, usando otros medios.

PEACOCK (1982, 18-19) también habla de un tipo de cerámica casera de Jutlandia hecha a mano por las mujeres; está cocida al aire libre, con la participación de los hombres, y se distribuye a caballo y en barco por toda la Europa del norte: Holanda, Noruega, Latvia, Estonia, Alemania hasta Berkin y Dresden, y en algunos casos, hasta Viena, a unos $1.000 \mathrm{Km}$ de su punto de origen. No obstante, en su distribución participan también comerciantes intermediarios.

En otro caso, en la localidad de Peruela (Provincia de Zamora, España), las mujeres modelan la cerámica a torno lento y, con la ayuda de los hombres, la cuecen en hornos simples que pueden tener una capacidad de 70 o de 150-250 piezas. No venden la cerámica en ferias, pero la llevan en burro a las aldeas locales, a Zamora y a veces hasta León o El Barco de Valdeorras (Galicia), a unos $150 \mathrm{Km}$.
También venden a comerciantes intermediarios que la distribuyen a zonas más distantes, como Burgos o Andalucía. Es notable que esta industria no es en estas comunidades la fuente principal de sustento, sino que siguen siendo aún de base agrícola (PEACOCK, 1982, 19-21).

Para Peacock, la existencia de esta forma de industria casera es un complemento de suplementar una economía pobre, en zonas poco fértiles o de agricultura poco desarrollada, y donde no existe la posibilidad de desarrollar otra clase de industria comercial, como minas, cestería o industria de salazones, por ejemplo (PEACOCK, 1982, 23-24).

También hay que notar que la atracción de esta cerámica reside en parte en su precio barato - se efectúa con poco coste, ya que hay poca inversión de capital, se hace durante una temporada corta, y casi todo es trabajo femenino, sin salario- y su resistencia al fuego, debido a la abundancia de desengrasantes (PEACOCK, 1982, 24-25). En este sentido debemos aceptar que una cerámica tan basta tiene su lugar y valor en el conjunto cerámico de las poblaciones, al igual que la hecha a torno rápido. El resto de la producción cerámica que distingue PEACOCK $(1982,9-10,25-46,91-128$ : talleres individuales, talleres nucleados y manufactoría) no atañen a nuestro estudio, porque los estudios etnográficos demuestran que se limitan a la producción de cerámica a torno rápido. En estos niveles más altos de producción el trabajo lo realizan en exclusiva los hombres, ya sea en uno o varios talleres, con el uso de hornos y es la fuente principal de subsistencia del productor o productores, a través de la producción de formas específicas y con la participación de negociantes intermediarios en la explotación de un mercado distinto y, a veces, muy amplio.

Desde este punto de vista, trateremos de interpretar la importación y producción de cerámica hecha a mano en torno lento en la zona alicantina (?).

Hablaremos primero de las importaciones. Como ya hemos señalado, la cerámica de tres o quizá cuatro de los diez grupos clasificados en la tipología de Fulford, forma parte de los conjuntos cerámicos de algunos yacimientos, desde época altoimperial en algún caso (grupo 1), pero en su mayoría a partir. de la primera mitad del siglo VI (grupos 2, 3 y 4 [?]). Sólo la cerámica del grupo 2 tiene una distribución algo mayor por el interior. De esta cerámica de importación, sólo se conoce el origen del grupo 1, en la isla de Pantellería. 
El caso de la cerámica de Pantellería ilustra perfectamente las posibilidades de un comercio de cérámica de esta clase y de su importancia en el mercado cerámico de su época. La producción y exportación a ultramar de la cerámica de Jutlandia es un paralelo moderno bastante válido en este caso. Igualmente debemos explicar el comercio de la cerámica de Pantellería como resultado de la escasa fertilidad agrícola de la isla. También está claro que los negociantes jugaban un gran papel en la exportación de la cerámica.

En el caso de la cerámica de importación no hay ninguna duda de que se trata de un comercio a partir de un centro, pero en el caso de la cerámica hecha a mano a torno lento hallada en los yacimientos alicantinos, hay que plantearse hasta qué punto podemos considerarla como resultado de un comercio local o regional, y no simplemente como cerámica de producción casera, hecha en los yacimientos mismos. Es aquí donde surge la importancia de una definición exacta de la pasta y técnicas de modelado de cada clase de cerámica, junto con el estudio de la distribución de sus formas.

Si no estamos equivocados en nuestras observaciones sobre la técnica del modelado de las piezas, la cerámica del grupo 4 está hecha a torno lento, pero hay que decir que es de una técnica bastante desarrollada en comparación con la cerámica de los grupos 5-9. Se destaca también por su fecha claramente más antigua, anterior al siglo $\mathrm{V}$ (por su ausencia en los yacimientos de altura) y quizá con una fecha inicial en el siglo III.

La pasta invariable, el uso del torno lento y la restricción a solamente dos formas son indicaciones de la concentración de un centro de industria casera en la producción de una clase de cerámica para un mercado que hasta ahora se limita a.unos cuantos yacimientos costeros cerca de Alicante. Por no conocer suficientemente su distribución, aún no podemos decir si se trata de un producción local o regional (¿de Murcia?) con una distribución costera.

Un elemento característico en los conjuntos de todos los yacimientos de altura, que aparecen como asentamientos casi repentinamente a partir del siglo $\mathrm{V}$, es la cerámica del grupo 5. Tiene una distribución amplia a lo largo del Vinalopó y desde el mar hasta Alcoy y Calpe. Quizá es el caso más claro del comercio de cerámica de una industria casera, en este caso,de cerámica modelada a mano. La pasta con su característico desengrasante de mica dorada nos sugiere un centro de origen cercano a Jumilla
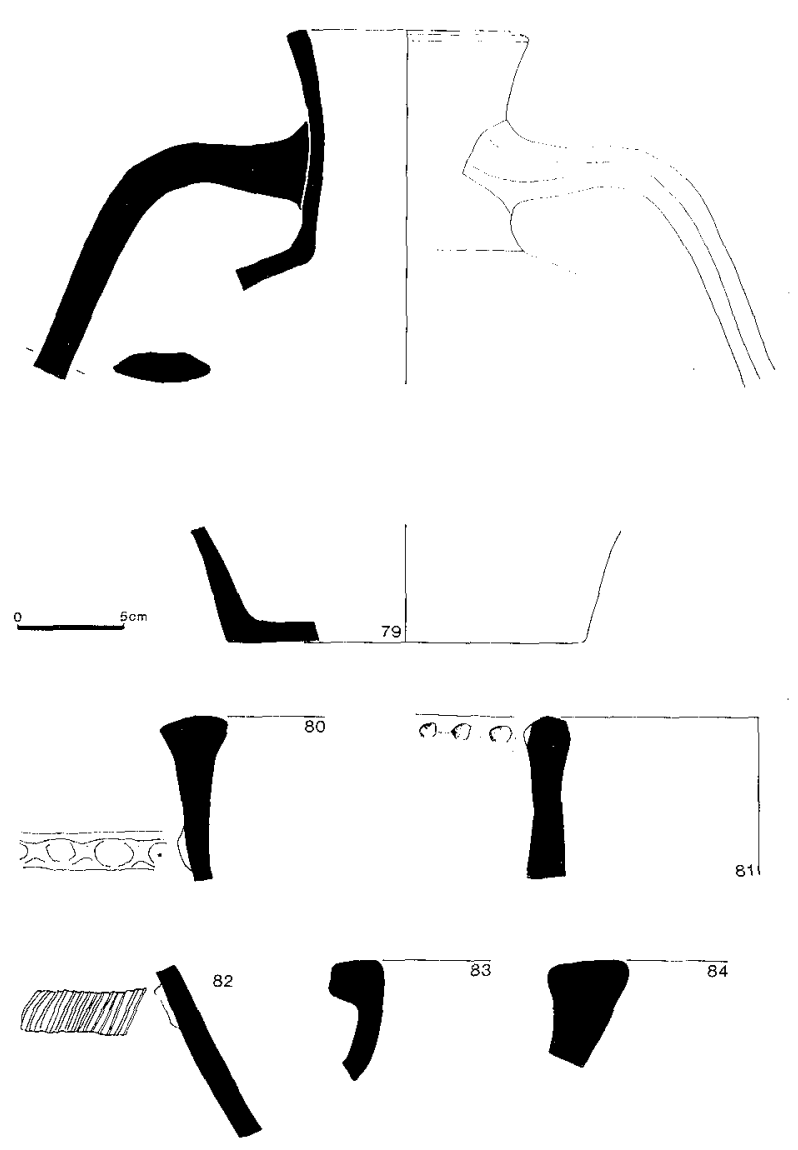

Fig. 12: 79. CR 1979-867; 80. MOL 346; 81. MOL 417; 82. CAST (Elche) 47; 83. CAST (EIche) 55; 84. CAST (Elche) 54.

(Murcia), pero faltan aún muchos estudios para averiguar si la distribución en los yacimientos costeros es debida al transporte marítimo de esta cerámica. Ni siguiera conocemos su distribución en Murcia, o por lo menos en la zona de Jumilla, donde deberíamos encontrar una presencia mayor y más variada de formas; tendremos incluso problemas en su identificación, ya que es indistinguible de la cerámica del Bronce. Creemos que la distancia desde Murcia hasta la costa de Alicante es bastante mayor a la normal para una distribución basada simplemente en el transporte de la cerámica por parte de los productores, y que por tanto debía haber negociantes que desempeñaban un papel importante en su comercio. Tampoco podemos ignorar la posible existencia de ferias locales para su venta y dispersión.

Al comenzar el siglo VI aparece una nueva clase de cerámica modelada a mano (el grupo 7), con una 
distribución también marcada por los yacimientos de altura en el valle del Vinalopó. No lo hemos encontrado en nuestras prospecciones de las villas en el llano, pero notamos su presencia en la necrópolis tardía de Vistalegre (Novelda) y en la villa de La Ermita de Fontcalent. Si se compara con la única forma (7.6) que aparece en la mayoría de los yacimientos, en La Alcudia / Illici existe tal variedad, $\mathrm{y}$ tantas formas decoradas, que puede pensarse en la existencia de una producción local en este yacimiento, que constituiría el centro de distribución de esta forma cerámica.

Creemos por tanto que no se trata de un ejemplo de producción casera en todos los yacimientos, por lo menos en el valle del Vinalopó. Pero si salimos de esta zona, encontramos en Arneva una clase de cerámica (el grupo 9) con una pasta indistinguible de la del grupo 7 y con formas idénticas, aunque aparecen también algunas formas y detalles técnicos que son exclusivos de este yacimiento.

Al parecer, la pasta 7 se encuentra en otras zonas de la provincia, y aquí existe una producción contemporánea en dos centros de cerámica con las mismas características (Formas 7.6/9.3,7.7/9.6,7.10 19.7), junto a una serie de formas personales para mercados distintos. También hemos visto en el material procedente del yacimiento de Bigastrum/Cabeza de Roenas (Murcia), cerámica de una pasta y forma similar al 7.6, pero teniendo solamente este punto de referencia no podemos plantear la posibilidad de una producción o comercio de la cerámica del grupo 7 -o de una clase de cerámica similar-en la región de Murcia; tan sólo podemos demostrar la dispersión amplia de la cerámica con estas características.

Quizá un caso de cerámica hecha a mano con una distribución puramente local es la cerámica del grupo 8, que hemos encontrado únicamente en la villa de La Ermita de Fontcalent, junto a la cerámica del grupo 7, aunque sin ninguna relación estratigráfica con ella. Podríamos encontrarnos ante un caso de producción casera; aunque la presencia de formas del grupo 7 podría ser un argumento en contra, porque no tendrían un lugar en un yacimiento que fabrica su propia cerámica, existe la posibilidad de que en ocasiones se completara la producción casera comprando cerámica de otro lugar. En todo caso hay que decir que la distribución del grupo 8 es muy reducida en comparación con la cerámica de los otros grupos.

Hasta ahora no hemos tratado el problema de la perduración de la cerámica de los grupos 5-9. La distribución del grupo 5 en los mismos yacimientos que la cerámica del grupo 7 nos hace difícil determinar su fecha final, pero, pensamos que, aunque existe producción de cerámica del grupo 5 en el siglo VI, no iría más allá de principios de este siglo, por su poca frecuencia en el vertedero de Benalúa (1971).

En cuanto a la perduración de los grupos 7-9, debemos primero considerar los cambios que afectaron a las importaciones de cerámica fina, hasta ahora nuestro principal elemento para fechar la cerámica común.

Al parecer (KEAY, 1984, 417-435. FULFORD y PEACOCK, 1984, 255-262. REYNOLDS, en prensa, 92), una consecuencia grave de la reconquista bizantina del norte de África fue el estrangulamiento de la economía de la provincia de África, que durante la época vándala había dirigido su producción agrícola y cerámica (ánforas y ARS) hacia las costas de Hispania, aprovechando la inexistencia del impuesto agrícola de la annona. Los bizantinos cortaron este comercio, redistribuyendo el territorio y reintroduciendo la antigua annona para servir a la capital Bizantium. (ver PROCOPIUS, Cap. XVIII). El resultado fue el cese rápido de las exportaciones hacia Hispania, por lo que no encontramos formas muy tardías de ARS en los yacimientos de la Península Ibérica (formas típicas de los finales del siglo VI en adelante: Hayes 91D, 104C, 105, 107-109). Es posible que continuara, hasta cierto punto, el uso de formas antiguas de ARS, pero en el siglo VII, y quizá desde c. 575, debemos encontrar yacimientos «activos», pero sin ARS.

¿Si existieran yacimientos de fechas inmediatamente posteriores a las fechas de las últimas importaciones de ARS en la región, qué cerámica encontraríamos en estos yacimientos? El caso más llamativo es el yacimiento de El Monastil; aunque la cerámica del grupo 7 no parece formar parte del conjunto cerámico de las antiguas excavaciones (donde hay una ausencia de ARS del siglo VI), las formas 7.6 y 7.9/10 han aparecido en las excavaciones recientes en el yacimiento (A. Poveda, 1984), todavía sin ARS del siglo VI, y creemos que se fecha en el siglo VII, en la época de la fundación y desarrollo de la iglesia y obispado de Ello (atestiguado desde 610 y hasta 673 en las listas de los concilios visigóticos (MANSI, 1762), que se ha identificado, correctamente pensamos, con este yacimiento (LLOBREGAT, 1977; 1983, 235-237).

Hay otros casos. Según RAMOS FERNÁNDEZ (1983, 148, 154-159), en sus excavaciones en La 
Alcudia se halló cerámica modelada a mano (de los grupos 2,5 y 7 , al parecer) en un contexto sin ARS, aunque no hay una falta de ARS del siglo VI en el yacimiento (REYNOLDS, inédito). También, hasta ahora, la cerámica de los grupos 7 y 8 ha aparecido en la villa de La Ermita de Fontcalent sin ARS tardío, y creemos que la cerámica tiene una fecha a partir de c. 575 y dentro del siglo VII, según el argumento del cese de las importaciones de ARS. Aunque pensamos que la cerámica de Arneva (grupo 9) puede tener una fecha a partir de c. 575, por las mismas razones, no estamos seguros de que se trate de cerámica tardorromana, prefiriendo considerarla, por el momento, como cerámica de época islámica.

En efecto, siempre hemos pensado que ejemplares de la forma 7.6, que hemos encontrado en una serie de yacimientos - algunos con ARS del siglo $\mathrm{VI}$ - podrían fecharse en época islámica en La Moleta, El Castellar (Elche), El Sambo, Els Castellarets y, ahora la necrópolis de Vistalegre (Aspe), pero sin ninguna prueba, ya que la cerámica del grupo 7 es invariable y, hasta ahora, no podemos distinguir ejemplares de distintas épocas (los ejemplares de El Monastil, por ejemplo, que fechamos en el siglo VII, no se diferencian de las piezas del vertedero de Benalúa, que fechamos en la primera mitad del siglo VI).

Un buen argumento en favor de la datación de la cerámica de los grupos 7 y 9 en la época islámica es la aparición, en niveles de fundación de un edificio del siglo IX excavado recientemente por $\mathrm{R}$. Azuar en La Fonteta de Guardamar, de una forma de cerámica hecha a mano o a torno lento, con base plana y paredes inclinadas hacia adentro, decorada por el exterior con un peinado de líneas onduladas; es una forma que nos recuerda instantáneamente la forma 7.6 (fig. 11,69; hay un ejemplar entero de Guardamar en el Museo Provincial de Alicante). Es una forma que encontramos en los conjuntos de El Castillo de Santa Bárbara (Alicante), Castillo del Río (Aspe), El Castellar y El Sambo. También lo hemos visto en las vitrinas del Museo Provincial de Murcia, procedente de los yacimientos de El Monte de Sta. Catalina (Verdolay), Cabezo de Víboras (Mazarrón) y posiblemente de «Las Yeserías» (Lorca).

En efecto, hay una serie de formas de cerámica de pasta y características similares que creemos pueden ser contemporáneas de la cerámica de Guardamar (fig. 11, 73-75, de La Alcudia, colección de P.
Ibarra; fig. 11,72 de Els Castellarets de Busot), dos ánforas del Castillo de Aspe (ilustramos una en fig. 12,79; hemos encontrado asas similares en $\mathrm{La}$ Moleta), y una forma vidriada por el interior (fig. 11,70, de La Alcudia; conocemos otro ejemplar del Convento MM. Agustinos [?], Murcia, en el Museo Provincial de Murcia). Incluimos aquí también una pieza sin procedencia, del Museo del Palacio de Altamira (Elche) (fig. 11,71).

También ilustramos una forma hecha a mano de El Castellar (Alcoy), que igualmente muestra similaridades con la forma 7.6 (fig. 11,76), que TORRO Y ABAD $(1984,279)$ fecha en el siglo $X$, siguiendo los argumentos de ZOZAYA (1979). En la misma pasta rojo-marrón, con mica dorada muy fina, abundante, encontramos una forma similar (fig. $11,77)$ y bases de la misma forma en Els Castellarets de Busot, y hemos recogido dos bases más, pero con mica plateada, en El Castillo de Santa Bárbara. Quizá son del mismo centro de producción que una forma muy similar, clasificada en la tipología de cerámica islámica de Almería (DUDA, 1972, 413, Abb.4.n y o, Tafel 73, a y b. «Unglasierte rote Ware». Ver también DUDA, 1971, Abb.4.q, Tafel $74 \mathrm{~h}$ ). Finalmente hemos inventariado una forma similar aunque con asa horizontal, y vidriado en parte, procedente de Els Castellerets de Busot (fig. 11, 7-8).

Lo que queremos comentar aquí es que la existencia de esta serie de formas modeladas a mano o a torno lento, de fecha islámica, quizá desde el siglo IX (según las fechas de Azuar para la cerámica de Guardamar), es un indicio de la perduración de formas y técnicas de cerámica hecha sin torno tardorromana, durante el siglo VIII, partiendo de modelos todavía existentes en el siglo VII en yacimientos como El Monastil.

También podemos anotar que mucha cerámica islámica a torno tiene sus orígenes en la cerámica tardorromana. Así ocurre con la decoración peinada de líneas onduladas, las formas típicas de tinajas y alcadafes con decoración de bandas aplicadas e impresas o líneas onduladas (AZUAR RUIZ, 1983, fig. 7c y Fig. 8b; cerámica similar en el vertedero de Benalúa); el candil de piquera larga (AZUAR RUIZ, 1985, lám. XLI; para la versión tardorromana ver REYNOLDS, en prensa, lucerna de tipo $\mathrm{D}$, de importación, fechada en la primera mitad del siglo VI); las jarras y ánforas islámicas en general, que parten de modelos tardorromanos corrientes en el Mediterráneo, como las ánforas LRA 1 y LRA 
2 (RILEY, 1983, 212-216, 217-219. KEAY, 1984, $268-278,352-357)$ y jarras o anforillas tardorromanas de la zona alicantina (REYNOLDS, inédito).

Teniendo en cuenta lo que sabemos de la cerámica islámica, y a modo de resumen, proponemos el siguiente esquema en un intento de enfrentarnos al problema de la perduración de la cerámica local y regional tardorromana y del desarrollo inicial de la cerámica islámica en la zona, que creemos están intimamente relacionadas (ver AZUAR RUIZ, 1983, 368. TORRO Y ABAD, 1984, que están de acuerdo).

A partir del siglo VI, los yacimientos se pueden agrupar según sus conjuntos cerámicos de esta forma:

1. Yacimientos con ARS y cerámica tardorromana modelada a mano del grupo 7 , fechados $\mathrm{c}$. 500-550/575, según el ARS (por ejemplo los vertederos de Benalúa). Hay una posible perduración del grupo 6 al principio de este siglo.

2. Yacimientos sin ARS del siglo VI, con cerámica del grupo 7 (Formas 7.3/7.4, 7.6 y 7.9/10) (El Monastil, en la época del obispado de Ello), y del grupo 8 (La villa de La Ermita de Fontcalent), que fechamos a partir de c. 575 y dentro del siglo VII. Si nos equivocamos al fechar la cerámica del grupo 9, de Arneva, en época islámica, es probable que sea contemporánea de la cerámica de esta sección.

3. Yacimientos con ARS del siglo VI, pero que deben fechar también más allá de c. 575, y después del siglo VII, ya en época islámica, donde encontramos la forma 7.6 y versiones que clasificamos como «antiguas» de la tinaja clásica islámica (fig. 12, 80-84); estos dos elementos los encontramos en el Castillo de Sta. Bárbara, La Moleta, El Castellar (Elche), El Sambo, Els Castellarets (Petrel); y también encontramos una serie de anforillas y jarras, pintadas con bandas rojo-marrones, de pasta ocre amarillento con desengrasantes angulosos (rojomarrón-negro) de arcilla triturada (?) que encontramos en El Sambo, la Necrópolis de Vistalegre y La Moleta (?) También hay una versión de la forma con base plana de Guardamar, en esta pasta, en El Sambo. AZUAR RUIZ $(1983,368)$ fecha esta cerámica pintada a los siglos X y XI; igualmente se incluye en este grupo la serie de formas islámicas hechas a mano o a torno lento, vidriadas y $\sin$ vidriar, con decoración peinada, que encontramos en Guardamar, el Castillo de Sta. Bárbara, La Alcudia, Castillo del Río, El Castellar (Elche), El Sambo y Els Castellarets de Busot. Como según Azuar, la cerámica de Guardamar se fecha en el siglo IX, consideramos por separado por el momento la forma con base plana de El Castellar (Alcoy), El Castillo de Sta. Bárbara y Els Castellarets de Busot, que según Torro y Abad se puede fechar en el siglo $\mathrm{X}$.

La cronología de estos yacimientos es muy preocupante. Tenemos varios puntos de referencia: el primero, una fecha posterior al siglo VII para todos estos elementos, porque están ausentes en El Monastil; el segundo, una fecha del siglo IX para la cerámica de Guardamar, y, el tercero, una fecha a fines del siglo IX/X-XI para la cerámica vidriada de importación, que sólo se ha documentado en Els Castellarets y El Castillo de Salvatierra (ver la siguiente sección). En todo caso, vemos casi imposible fechar estos yacimientos con tantos elementos variables sin poder distinguir lo que es contemporáneo.

Sin embargo, nos atreveríamos a proponer que algunas formas del grupo 7 (7.6, 7.7 [?] y 7.10 [?]) continuaron durante el siglo VIII, y que quizá sea también contemporánea la cerámica de Arneva (grupo 9). En el siglo IX, o quizá un poco antes, en el siglo VIII (ya que la cerámica de Guardamar estaba en los cimientos del edificio excavado), aparece la serie de cerámica islámica típica de Guardamar, El Castellar, La Alcudia, etc., que creemos puede ser de importación tal vez de Murcia o Almería. No descartamos la posibilidad de que la cerámica de Arneva sea contemporánea de esta cerámica. Probablemente contemporánea es la serie de cerámica pintada de El Sambo, etc., recordando en este aspecto la versión en esta pasta de la forma de Guardamar. También con una pasta parecida, con desengrasantes de ocre, debemos incluir y fechar como contemporáneas las tinajas de El Sambo y de La Moleta, que se acercan bastante a los modelos tardorromanos, y algunas ánforas de La Moleta y las dos de El Castillo del Río (fig. 12,79). Si la cerámica de Arneva es en realidad contemporánea, mostraría también la contemporaneidad probable de las formas 7.6, 7.7 y 7.10.

Aunque tiene la misma cerámica islámica hecha a mano que la de Guardamar, etc., sospechamos que el yacimiento importante y extensivo de El Castellar (Elche), que se compara marcadamente con los poblamientos islámicos que describe GUICHARD (1983. Ver PÉREZ VARO y otros, 1982, 69, para un plano del yacimiento), tiene una cronología más amplia, alcanzando el siglo X, y quizá el XI, contemporáneo en estas fechas con Els Castellarets 
(Petrel). En estos dos yacimientos, en contraste con El Sambo y La Moleta (fig. 11, 80-81), las tinajas parecen ser más semejantes a las formas clásicas islámicas (fig. 11, 82-84. Ver IBARRA, 1926, para fotos de la cerámica de La Moleta y El Castellar).

4. Yacimientos con cerámica islámica vidriada califal de importación de los fines del siglo IX o principios del siglo $\mathrm{X}$ y XI, que encontramos en El Castillo de Salvatierra (Villena), y de los siglos X-XI en Els Castellarets (Petrel) (AZUAR RUIZ, 1983, 358, $359,364,378)$. Como ya hemos señalado, quizá El Castellar (Elche) debe incluirse en este grupo, aunque no se ha encontrado esta cerámica en el yacimiento, hasta ahora. Ver también El Castellar (Alcoy) y otros yacimientos alcoyanos fechados en el X (TORRO Y ABAD, 1984, 282-283).

Insistimos que sólo hemos propuesto una serie de teorías sobre la problemática de la cerámica y los yacimientos islámicos y que falta un tratamiento amplio y detallado sobre el tema. Aún en el caso de estar totalmente equivocados en las fechas que hemos propuesto, esperamos haber destacado los puntos que son significativos y que servirán para la base de un futuro trabajo más científico (esperamos con gran interés la tesis doctoral de nuestro amigo R. Azuar Ruiz sobre la arqueología islámica y medieval de la zona alicantina).

Confiamos en que este artículo haya mostrado en parte el valor del estudio de una clase de cerámica que hasta ahora ha recibido menor atención de la que se merece. Hemos señalado su claro interés como dato cronológico, especialmente importante en las «épocas oscuras» a partir de la segunda mitad del siglo VI, cuando terminan bruscamente las importaciones de cerámica fina. En este sentido, es importante hacer ver que es muy probable que la cerámica fina (ARS) esté ausente en los yacimientos desarrollados durante la «reconquista» bizantina.

El uso de paralelos etnográficos nos puede proporcionar datos muy significativos sobre el desarrollo y organización de la producción y posible comercio local y regional de esta clase de cerámica, aparte de mostrar de qué forma los yacimientos de la región participan en el comercio general de cerámica hecha a mano o a torno lento en el Mediterráneo en época tardorromana.

Para comprender mejor el escenario local y regional es necesaria la publicación de cerámica similar en las regiones que lindan con la provincia, y en la Península Ibérica en general, y es esencial la iden- tificación precisa de las partes, y no solamente de las formas, para aislar la serie de productos de cada centro. Una descripción de «cerámica basta con mucho desengrasante» es totalmente insuficiente. Incluso el estudio más detallado de las pastas que hemos realizado nos parece insuficiente en algunos casos, y será necesario al final utilizar un método de análisis mucho más crítico, como «Heavy Mineral Analysis» (PEACOCK, 1967, 1970, 1982, 85, 88, $90,98,101)$ para diferenciar entre pastas indistinguibles macroscópicamente (especialmente en la comparación de la cerámica de los grupos 7, 9, y cerámica de época islámica hecha a mano o a torno lento).

También debemos reconocer que tendremos dificultades a la hora de identificar los centros de producción, ya que el modelado y la cocción de esta cerámica deja pocos rastros materiales (PEACOCK, $1982,14)$. Es típico, en los casos modernos que se conocen, el modelado sin torno o usando un torno lento de madera, que no se conservaría, y la cocción simplemente al fuego abierto o quizá en un horno doméstico, como se ha documentado en las aldeas de Farinole y Canaja (Córcega) (PEACOCK, $1982,17)$. Si tenemos suerte, es posible que en algunos casos se haya construido un horno simple de piedra, como los de Peruela.

Para comprender mejor el desarrollo de la cerámica y del asentamiento a partir del siglo VII es necesario un programa de excavaciones de yacimientos que consideramos como claves en este sentido, como son El Monastil (para el siglo VII), y los yacimientos de Arneva, El Sambo, La Alcudia y El Castellar (Elche) (para los siglos VIII-X). También en contra a lo que se ha supuesto siempre (RAMOS FERNÁNDEZ, 1975), creemos que el yacimiento de La Alcudia/Illici tuvo una vida más allá de los siglos VI/VII y que continuó su desarrollo en época islámica, antes que la ciudad árabe de Elche.

Finalmente, PEACOCK $(1982,81,89)$ ha demostrado que existió el comercio de cerámica hecha a mano en épocas prehistóricas en las Islas Británicas, y no simplemente una producción casera para el uso individual de los productores. Teniendo esto en cuenta, ¿hasta qué punto sería comparable el desarrollo de la producción de cerámica sin torno tardorromana e islámica con la producción de esta cerámica en la época del Bronce en esta región?

Londres, junio de 1985 


\section{CÓdIGOS PARA LA CERÁMICA DE LOS YACIMIENTOS:}

SP: Santa Pola (Museo Arqueológico de Alicante).

FC: Villa de la Ermita de Fontcalent (Museo Arqueológico de Alicante).

BEN/O: Vertedero de Benalúa (1971) (Museo Arqueológico de Alicante).

BEN.83: Vertedero de Benalúa (1983) (Museo Arqueológico de Alicante).

ALT: Material en el Museo del Palacio de Altamira. Elche.

AL: La Alcudia (Museo de La Alcudia).

AL.ALT: La Alcudia (Museo del Palacio de Altamira).

CAST.ALT: El Castellar (Elche) (Museo del Palacio de Altamira).

+ CAST: El Castellar (Elche) (Museo Arqueológico de Alicante).

CAST DE BUSOT: Els Castellarets de Busot (Museo Arqueológico de Alicante).

CR: Castillo del Río. Aspe. (Museo Arqueológico de Alicante). + MOL: La Moleta (Elche) (Museo Arqueológico de Alicante).

CASTELLAR: El Castellar (Alcoy).

\section{BIBLIOGRAFÍA}

ABAD CASAL, L., 1983; «Arqueología romana del País Valenciano: panorama y perspectivas», Primeras Jornadas de Arqueología de la Universidad de Alicante. Alicante.

- 1984; Los orígenes de la ciudad de Alicante. Alicante.

ABELLÁN SORIANO, P. y otros: «Begastri 1984» - Antigüedad y Cristianismo. Murcia, 1984.

AZUAR RUIZ, R., 1983; «Panorama de la arqueología medieval de los valles alto y medio del Vinalopó (Alicante)». Lucentum, II, 349-383.

- 1985; Castillo de La Torre Grossa (Jijona). Catálogo de fondos del Museo Arqueológico. I. Diputación Provincial de Alicante. Alicante.

CERDÁ BORDERA, F., 1983; «Contribución al estudio arqueológico de La Foia de Castalla (Alicante)», Lucentum, II, 69-90.

DUDA, D., 1971: «Pechina bei Almería als Fundort spanisch-islamischer Keramik», Madrider Mitteilungen, 12, 262-288.

DUDA, D., 1972; «Die frühe spanische-islamische Keramik von Almería», Madrider Mitteilungen, 13, 345-432.

FULFORD, M. G., y PEACOCK, D. P. S., 1984; Excavations at Carthage: The British Mission, Vol. I(ii). The Avenue du Président Habib Bourguiba, Salammbo: The pottery and other ceramic objects from the site. Sheffield.

GONZÁlEZ BLANCO, A., y otros, 1983; «La ciudad hispano-visigoda de Bigastri (Cabezo de Roenas, CehegínMurcia). Dos primeras campañas de aproximación al yacimiento», Congreso Nacional de Arqueologia, XVI, Zaragoza, 1011-1022.

GONZÁLEZ PRATS, A., 1985; «Aportaciones al conocimiento del Portus Illicitanus. Reseña de los trabajos de urgencia de 1976: La terra sigillata», Lucentum, III, 1984, 101-134.

GUICHARD, P., 1983; "Geographie historique et histoire sociale des habitats fortifiés ruraux de la region valencienne», en Habitats fortifiés et organisation de l'espace en Mediterranée médiévale (Lyon), 87-93.

HAYES, J. W., 1972; Late Roman Pottery. London.

- 1976; «Pottery-stratified groups and typology». En HUMPHREY, J. H., ed.; Excavations at Carthage 1975 conducted by the University of Michigan, I, 47-123. Tunis.

- 1980; Supplement to Late Roman Pottery. London.
IBARRA, P., 1926; Elche: materiales para su historia. Cuenca. KEAY, S. J., 1984; Late roman amphorae in the western mediterranean. A typology and economic study: the Catalan evidence. British Archaeological Reports, International Series, S196. Oxford.

LAMBOGLIA, N., 1958; «Nuovi osservazioni sulla "terra sigillata chiara"". Rivisti di studi Liguri, XXIV, 257-330.

- 1963; "Nuovi osservazioni sulla "terra sigillata chiara"”, Rivista di Studi Liguri, XXIX, 145-212.

LLOBREGAT, E. A., 1967; "Datos para el estudio de las cerámicas de época imperial romana». Congreso Nacional de Arqueología, X, Mahón, 366-378.

- 1970; «Materiales hispano-visigodos del Museo Arqueológico Provincial de Alicante», Papeles del Laboratorio de Arqueología de Valencia, 10, 189-204.

- 1976; «El origen romano de Elda». Alborada, XXII. Elda.

- 1977; La primitiva cristiandad valenciana. Valencia.

- 1980: Nuestra Historia. Vol. II. Valencia.

- 1983 a; «Relectura del Revennate: dos calzadas, una mansión inexistente y otros datos de la geografía antigua del País Valenciano», Lucentum, II, 225-242.

- 1983 b; «Las épocas paleocristiana y visigoda», Primeras Jornadas de Arqueología de la Universidad de Alicante. Alicante.

LOBREGAD COLLADO, M. T., y SÁNCHEZ FERNÁNDEZ, M. J., 1985; «Estudio preliminar sobre las ánforas del Portus Illicitanus», Lucentum, III, 1984, 135-153.

MANSI, J. D., 1762; Sacrorum Conciliorum nova et amplissima collectio. Florenzia. Reedición de WELTER, H., París y Leipzig, 1901

PEACOCK, D. P. S., 1967; «Heavy mineral analysis of pottery: a preliminary report», Archaeometry, 10, 97-100.

- 1970; «The scientific analysis of ancient ceramics: a review», World 1rchaeology, 1, 375-389.

- 1982; Pottery in the Roman World: an ethnoarchaeological approach. Singapore.

PEREZ VARO, y otros, 1982; «El Castellar: introducción a su estudio», por el Grupo Ilicitano de Estudios Arqueológi$\cos$, Revista de Investigación y Ensayos del Instituto de Estudios Alicantinos, 37, 67-84.

POTTER, T. W., 1979; The changing landscape of South Etruria. London.

POVEDA NAVARRO, A., inédito; La terra sigillata de Elda. Tesis de Licenciatura, Universidad de Alicante, 1984.

POVEDA NAVARRO, A., y RIBERA LACOMBA, A., 1985; «Marcas de Terra Sigillata de Elda», Saguntum, 19, 301-310.

PROCOPIUS, The Secret History, translated by ATWATER, $R$. New York, 1927.

RAMOS FERNÁNDEZ, R., 1975; La ciudad romana de Illici. Estudio arqueológico (Instituto de Estudios Alicantinos). Alicante.

- 1976; «Las villas de la centuriación de Illici», Symposion de las ciudades Augústeas, Zaragoza, 209-216.

- 1983; «Estratigrafía del Sector 5-F de La Alcudia de Elche», Lucentum, II, 147-172.

REYNOLDS, P., en prensa; Catálogo de los materiales aparecidos en excavaciones en Benalúa (Alicante) (1971): La cerámica fina. Catálogo de los fondos del Museo Arqueológico de Alicante, 2.

- inédito; La arqueología romana del valle del Rio Vinalopó, Alicante. Tesis doctoral, Institute of Archaeology, London.

RILEY, J. A., 1983; «The coarse pottery from Berenice» in LLOYD, J. A., ed., Excavations at Sidi Khrebish, Benghazi (Berenice). Supplements to Libya Antiqua V, vol. II, 91-467. Tripoli. 
SÁNCHEZ DE PRADO, M. D., 1985; «El vidrio romano en la Provincia de Alicante», Lucentum, III, 1984, 79-100.

SÁNCHEZ FERNÁNDEZ, M. J., 1983; «Cerámica común del Portus Illicitanus», Lucentum, II, 285-318.

SECCIÓN DE ARQUEOLOGÍA-C. E. E., 1972; «Carta arqueológica del valle de Elda (Alicante), Archivo de Prehistoria Levantina, XIII, 199-208.

SOLER GARCÍA, J. M., 1967; «La romanización de la comarca villenense», en Villena, n. ${ }^{\circ} 17$.
TORRO Y ABAD, J., 1984; «Arqueología medieval de Alcoi y su entorno", en Alcoy, Prehistoria y Arqueología. Cien años de investigación, 277-309. Alcoy.

VIVES, J., 1927; Concilios visigóticos.

ZOZAYA, J., 1979; «Áperçu général sur la céramique espagnole», I Coloquio Internacional de Cerámica Medieval del Mediterráneo Occidental, Sophie-Antipolis, 265-296. 